This is the peer reviewed version of the following article: Raess, D. and Sari, D. (2018). Labor Provisions in Trade Agreements (LABPTA): Introducing a New Dataset, Global Policy 9(4): 451-466, which has been published in final form at https://doi.org/10.1111/1758-5899.12577. This article may be used for non-commercial purposes in accordance with Wiley Terms and Conditions for Use of Self-Archived Versions.

\title{
Labor Provisions in Trade Agreements (LABPTA): Introducing a New Dataset
}

\author{
Damian Raess \\ SNSF Assistant Professor \\ World Trade Institute \\ University of Bern \\ Hallerstrasse 6 \\ 3012 Bern $(\mathrm{CH})$ \\ Damian.Raess@wti.org \\ \&
}

School of Politics, Economics and International Relations

University of Reading

Whiteknights Campus

Reading RG6 6AA (UK)

d.raess@ reading.ac.uk

\author{
Dora Sari \\ $\mathrm{PhD}$ candidate \\ University of Geneva \\ Boulevard du Pont d'Arve 40 \\ 1211 Genève $(\mathrm{CH})$ \\ Dora.Sari@etu.unige.ch \\ $\&$ \\ Labor and Worklife Program \\ Harvard Law School \\ 8 Mt. Auburn Street \\ 02138 Cambridge, MA (USA) \\ dsari@law.harvard.edu
}

\begin{abstract}
Damian Raess specializes in the international political economy of labor. He is the project leader of the research projects 'A Social Clause through the Back Door: Labor Provisions in Preferential Trade Agreements' (2014-2016), of which the LABPTA dataset is an output, and 'BRICS Globalization and Labor Protections in Advanced and Emerging Economies' (2017-2020).

Dora Sari is a PhD candidate in political science at the University of Geneva, focusing on global labor governance issues. She co-developed the Labor Rights Indicators hosted at the Pennsylvania State University's Center for Global Worker's Rights. She has extensive experience working with international organizations on labor- and social-related issues.
\end{abstract}


Abstract: Global labor policy through trade has begun to receive growing attention with the inclusion of labor provisions in preferential trade agreements (PTAs). Until recently there has been a shortage of available data that would adequately capture the variation that exists with respect to the scope and stringency of labor provisions, preventing scholars and practitioners from addressing key questions about the design and effects of the trade-labor linkage. This paper introduces a new dataset covering 487 PTAs from 1990 to 2015 coded against 140 distinct items pertaining to six main categories, presenting - to our knowledge - the most rigorous and fine-grained mapping of labor provisions. It also offers the first systematic description of key trends in the design and occurrence of those commitments. Our study shows that labor provisions have not only expanded in terms of their content and participating countries but that labor provisions have, although to a varying degree, also become more stringent over time. The provisions that have across all PTAs increased most steadily are the ones related to the institutional framework set up for the monitoring and implementation of labor commitments, becoming more specialized and more inclusive of third party involvement over time.

\section{Policy Implications:}

- Policy makers should actively invest in high-quality datasets and quantitative studies particularly regarding the socio-economic impact of labor provisions to design better targeted and more effective labor provisions in their trade agreements. Such datasets also provide a new tool for knowledge sharing and the training of relevant constituencies so that they develop a better understanding of existing approaches and practices for their ongoing or future trade negotiations.

- In line with the growing recognition of the importance of ex-post evidence-based assessment of the effectiveness of certain mechanisms, policy makers should also commit to the inclusion of provisions establishing regular impact assessment of the agreed labor provisions and their implementation.

- While the Singapore Ministerial Declaration (1996) of the WTO designated the ILO as the competent body to deal with labor standards in the context of international trade, the role of the ILO in this area remains circumscribed. Given its capacities as standard setter, provider of technical assistance, and holder of key expertise and initiatives in this area, policy makers should consider reinforcing the role of the ILO in the trade-labor linkage.

- Labor provisions in trade agreements have gained momentum in recent years, including in countries once staunchly opposed to their introduction, a movement that is likely to be reinforced under the UN Sustainable Development Agenda, particularly SDG goal 8 on inclusive growth and decent work. In view of the growing proliferation of labor provisions and arising new challenges such as parallel jurisprudence, institutional overlap, lack of coordination, WTO members should consider the renewed discussion and possible introduction of a labor clause at the multilateral level.

Acknowledgments: This paper is part of the Swiss Network for International Studies funded project 'A Social Clause through the Back Door: Labor Provisions in Preferential Trade Agreements' (Call for projects 2014; project coordinator: Dr. Damian Raess). We thank Joost Pauwelyn and Sonja Peters for helpful discussions and the latter for assistance with the coding of labor provisions. 


\section{Introduction}

The pendulum is swinging back, but not where the master expected it - and for good reason. Since the time Polanyi wrote his masterpiece The Great Transformation (2001 [1944]), capitalism has gone global again. While domestic labor market liberalization has proceeded unabated worldwide in recent decades, international labor regulation has made significant progress often beyond the headlines. The trade-labor linkage is a case in point. Since the early 1990s, preferential trade agreements (PTAs) increasingly incorporate labor provisions (LPs). ${ }^{1}$ These LPs link the benefits of enhanced market access to, for instance, the (effective) enforcement of internationally recognized labor rights. But there is much variation across time and space with respect to the scope and stringency of these LPs. While some PTAs include far-reaching and highly enforceable LPs, others only make scant or even no references to labor standards.

The objectives of this article are twofold: one is to introduce a new dataset on the design of Labor Provisions in Trade Agreements (LABPTA); the other is to document the evolution of the content and stringency of these LPs over time. The central idea is to provide a detailed and up-to-date picture for the better assessment of the trade-labor nexus on a global scale. To our knowledge, LABPTA is the most fine-grained and comprehensive mapping of the content of LPs in PTAs, allowing for extended analysis of the design and effects of (varying) LPs in PTAs.

While researchers have started to focus their attention on explaining the causes and consequences of variation in the design of PTAs, LPs have until recently either been neglected or not been the focus of systematic investigation (e.g., Dür and Elsig, 2015). Existing studies have tended to focus on a single case, be it a particular PTA or global player (e.g., Giumelli and van Roozendaal, 2016; Nyland and O'Rourke, 2005), or on a small-N comparative analysis of the United States (US) and the European Union (EU) (e.g., HafnerBurton, 2009; Kerremans and Gistelinck, 2009), all too often using and reproducing the narrow statement that US PTAs are enforceable with respect to labor standards whereas EU agreements are not (e.g., Postnikov and Bastiaens, 2014), which does not do justice to the broadening scope of enforceability in US PTAs and the enforceability, yet with variable geometry, of EU PTAs. The first broader based comparative analysis was done by the International Labour Organization (ILO) in 2009, an assessment that was extended in subsequent reports $(2013 ; 2016 ; 2017)$. The ILO's pioneering work in this domain, while providing detailed insights into the design and effectiveness of LPs in PTAs, on a 
methodological basis remains limited in two important ways: on the one hand it fails to introduce a comprehensive template for the mapping of LPs in PTAs; on the other hand it fails to carry out a systematic coding of the content of LPs in the available largest possible number of PTAs based on an integrated and encompassing conceptual and analytical approach.

Existing mapping exercises tend to focus on LPs as part of a broader objective to map nontrade issues (NTIs) in PTAs. Researchers engaged in such endeavor almost invariably face a trade-off between breadth and depth of issues covered that comes at the expense of a higher level of granularity in the coding of a single issue. Milewicz's (2016; Milewicz et al., 2018) dataset codes labor rights alongside human rights, environment, corruption, security and democracy for 522 PTAs signed over the period 1951-2009. Milewicz's mapping of LPs carries important limitations not only because it adopts a broad definition of labor rights that includes social security rights dealing with sickness, invalidity, old-age, industrial accident and unemployment, but also because the coding of the different NTIs, in spite of the distinction between provisions in the preamble and the main text of the agreement, remains very crude.

Lechner's (2016) dataset of NTIs design provides a novel coding for 474 PTAs signed since 1990, covering civil and political rights, environmental protection, and economic and social rights, the latter category including rights in the realms of development, education, health, labor, and social security. It is a significant improvement on Milewicz's dataset in that it covers a range of rights coded over the three dimensions of obligation, precision and delegation inherent to the legalization approach (Abbott et al., 2000). Lechner, while using a broader definition of LPs than we do, codes 25 items narrowly relating to labor protection (substantive-related commitments as well as institution and cooperation-related commitments) out of a total of 72 in the economic and social rights category. Yet, her template remains limited to the extent that the coding of obligation and delegation (i.e., issues of bindingenss, enforeceability, as well as third party involvement) is carried out in relation to economic and social rights in general, preventing us from knowing whether obligation and delegation apply effectively to LPs. Also, labor-related cooperation commitments are coded in a crude fashion with a single category.

Kamata (2016) examines the impact of labor clauses in PTAs on conditions of work for a sample of 223 PTAs from 1995 to 2011. The classification of PTAs with LPs builds on two criteria: 1) provisions that demand, urge, or expect the signatory countries to harmonize their domestic labor conditions and regulations with the internationally recognized standards; 
and 2) provisions that stipulate items over which the signatory countries will cooperate and the procedures for dispute settlement on labor issues. While an improvement on the binary coding of LPs, his classification remains too rudimentary to adequately capture the large variation in the design of LPs in PTAs. Among the shortcomings is the lack of details as to whether commitments are specific to any particular standards, the conflation between soft and hard mechanisms such as cooperation and enforceability, respectively, and the failure to distinguish between various degrees of enforceability.

Finally, Hofmann et al. (2017) constructed a novel database with detailed assessment of the content of 279 PTAs notified to the World Trade Organization (WTO) signed between 1958 and 2015. Their mapping covers 52 policy areas with a separate category for 'Labour Market Regulation'. It refers to provisions that pertain to the regulation of the national labor market and the affirmation of ILO commitments (a single item coded in a binary mode), and the enforcement of such provisions (coded on a 0-2 scale). In spite of their focus being more specific to labor rights, their methodological approach suffers from similar limitations as Kamata's approach.

In short, a rigorous and fine-grained approach to mapping LPs in PTAs is overdue. Our LABPTA template and dataset provide just that.

\section{Conceptualizing and measuring LPs in PTAs}

Given that there is no single approach as to what constitutes a 'labor' provision in PTAs, we opted for a narrow definition which has the advantage of drawing clear distinctions between labor and (broader) social provisions on the one hand, and between labor protection provisions and (broader) labor market regulation provisions on the other. In our conceptualization, LPs refer to rules and regulations that aim to protect and/or promote workers' rights and working conditions. In the context of PTAs, a labor issue is considered to be 'covered' by an agreement if the agreement contains a provision (i.e., chapter, article, paragraph or sentence) providing for some commitment in this field. In other words, we focus on labor protection provisions. Our definition thus excludes provisions dealing with social protection, such as social security (e.g., health, old age, unemployment, and family benefits) and education policy. It also excludes provisions relating to active labor market policies, such as the creation of employment opportunities, training, or 'supply-side' measures aimed at better matching labor supply and demand. Finally, because our focus is on the trade-labor linkage in PTAs, we ignore provisions regarding the free movement of 
workers and the treatment of migrant workers, as well as labor-related commitments in relation to investment.

The assessment of coverage, and the elaboration of our coding template for that matter, was done in three steps. First, we looked for the presence of LPs by way of the traditional search for keywords. ${ }^{2}$ This initial screening resulted in a classification of PTAs into three groups: PTAs with no LPs; PTAs with preambular LPs (or shallow LPs), that is, provisions found exclusively under the preamble or objectives parts of PTAs; and PTAs with comprehensive LPs, that is, LPs that go beyond the aspirational statements included in the preamble or objectives parts of PTAs. We considered LPs in the treaty texts, in side agreements on labor and Memorandums of Understanding (MoUs), without distinction between these different sources. However, the main treaty texts should establish a clear relationship to side agreements and MoUs for those to be considered. Concerning Action Plans that are agreed upon either simultaneously with or after the signing of the PTA concerned, ${ }^{3}$ those sources are considered but careful analysis is required in establishing the unilateral or reciprocal nature of the given LPs.

Second, we manually coded LPs in PTAs against our detailed coding template, which we designed using an inductive approach that was informed by the relevant literature. The template was fine-tuned as more agreements were added and new provisions found. This was a result of a series of exchanges among the authors, one of which is trained as a labor lawyer, and between them and a coder, a qualified lawyer with a strong understanding of the underlying concepts. We also benefited from several rounds of consultation with an established legal expert in international trade law.

Third, to test the reliability of our coding we crosschecked our results on 13 overlapping labor-related items from the coding by Lisa Lechner. The average Cohen-Kappa across the 13 dimensions is 0.75 (range: 0.63 to 0.88 ), which is recognized as substantive agreement. We are confident about the (high) reliability of our coding given our rigorous conceptual approach and efforts to revise it together with the associated coding, a process that has spanned over two years.

Our approach goes beyond existing mapping exercises in two ways. First, for the treaty texts we draw on the DESTA dataset (Dür et al., 2014), the most comprehensive of its kind in terms of the number of agreements covered on account of including both PTAs that have and have not been notified to the WTO. Our dataset contains information on as many as 140 distinct items pertaining to LPs in 487 PTAs among 165 countries over the period 19902015. To our knowledge, this dataset offers the most comprehensive data available in terms 
of the number of PTAs, countries and LPs covered. Second, we focus both on the scope (or breadth) of LPs, and the stringency of specific provisions through the assessment of their enforceability and the institutional framework set up for the monitoring and implementation of those. ${ }^{4}$

\section{The LABPTA coding template}

Our coding scheme (see Table A1 in the Online Appendix) is structured around six main categories: 1) Aspirational statements relating to LPs in preamble and objectives of the agreement (P); 2) Substantive commitments in relation to LPs (S); 3) Obligations in relation to substantive LPs $(\mathrm{O})$; 4) Enforceability of the substantive LPs (E); 5) Cooperation commitments over LPs (C); and 6) Institutions overseeing the labor-related commitments (I).

Substance and Cooperation relate to what matters in terms of substantive labor issues are being addressed in the relevant legal provisions (Bourgeois et al., 2007). In other words, it refers to the scope of labor protection provisions. Obligation, Enforceability and Institutions, however, relate to the stringency of labor-related commitments taken in these legal provisions. In a sense they qualify how far-reaching specific substantive commitments are. Whereas Obligations and Enforceability form the basis for assessing the degree of enforceability of specific labor-related commitments, Institutions capture the strength of the implementation and available softer means to promote compliance with commitments.

LPs in the preamble and the objectives parts of the agreements constitute aspirational statements, which is why we code them separately. Although still subject of academic debate (Hulme, 2016), LPs in preambles are predominantly considered to differ in terms of their legal effect from those found in other parts of the agreement in that they do not establish specific rights or obligations. Preamble statements do not contain binding obligations upon the parties, rather they 'offer a context for the signatories' overall objectives by introducing the agreement, setting out the motives of the contracting parties and the objectives to be accomplished by the provisions of the statutes' (Bourgeois et al. 2007, p. 13). The objective to 'improve working conditions' is by far the most frequent reference. To avoid double counting we do not code under P commitments to labor standards in the preamble if those same commitments are reiterated and elaborated in the main body of the agreements (where they get coded).

Under substantive commitments we list items related to international labor standards commitments and to domestic law commitments. The former consists of provisions derived from or related to internationally recognized labor commitments (fundamental rights at 
work, ${ }^{5}$ conditions of work, ${ }^{6}$ decent work ${ }^{7}$ ) and provisions concerning international instruments containing such commitments (e.g., ILO Conventions, ILO 1998 Declaration on Fundamental Principles and Rights at Work). ${ }^{8}$ The latter comprises three types of commitments, non-derogation, effective enforcement, and access to domestic courts. Nonderogation refers to commitments not to encourage trade through the weakening of labor laws. Effective enforcement of domestic laws refers to commitments to effectively enforce domestic laws. Access to domestic courts refers to guarantees concerning the right of workers or employers to fair, equitable and transparent domestic procedures under which their rights can be invoked and enforced. In total we have 20 different items coded under S, 17 pertaining to international and three to domestic commitments.

Under Obligations, following a strict legal interpretation of the treaty texts, we code the extent of obligations undertaken by the signatory parties. We are interested in whether or not the substantive commitments amount to legally binding obligations. Binding obligations are indicated by the use of terms such as shall, will, agree, undertake, ensure, realize, whereas commitments expressed with words such as 'should' or 'strive to ensure' indicate weaker commitments (see Bourgeois et al. 2007, p. 26). The 20 items under Substance are repeated under Obligations and coded accordingly.

Under Enforcement we focus on the model of dispute settlement mechanism (DSM) covering labor-related commitments. Building on a WTO taxonomy (Chase et al., 2016), we distinguish between political/diplomatic, quasi-judicial and judicial state-to-state DSM. Under the latter two, PTA members have an 'automatic' right ${ }^{9}$ of access to (often ad hoc) third party adjudication (quasi-judicial DSM) or standing judicial courts (judicial DSM). We separately code four types of remedies at the disposal of parties to enforce compliance with third party rulings, distinguishing between retaliation measures that can be imposed unilaterally, including trade sanctions, monetary compensation, and 'other appropriate measures', and those that cannot, as when the parties are explicitly required to find a 'consensual' solution to their dispute. The items under substantive commitments are repeated under each category of DSM and coded accordingly. Taking the remedies into account, we code a total of 64 items under Enforcement.

Under Cooperation we code the presence of any commitments in relation to provisions on labor-related cooperation. This includes the presence of any substantive laborrelated commitments if those are agreed by the parties as issues over which they will cooperate. The number of items covered under C (21) is slightly larger than the items under S as we found additional issues over which parties can agree to cooperate, including (reform of) 
labor laws, (promotion of) social dialogue, (reform of) labor administration and inspection system, and gender equality. ${ }^{10}$

Finally, Institutions depict the attributes that can determine the role and influence the institutional arrangements may have in the effective monitoring and implementation of laborrelated commitments. Such attributes include the type of bodies responsible for overseeing/implementing the commitments, their operation, the status of participants, the involvement of third parties, and the means available for the implementation of agreed commitments. We code whether the agreement foresees the establishment of a separate specialized committee responsible for the implementation and/or supervision of LPs (including contact points) or whether the body responsible for the monitoring/implementation of the entire PTA is also in charge of dealing with labor-related provisions ('regular committee'); whether the agreement stipulates regular meetings of the separate committee or whether the committee is convened on an ad hoc basis; whether the officials staffing the separate committee are high or low rank officials; whether the agreement authorizes the participation of key stakeholders, including the social partners, the ILO, NGOs, or other third party organizations; and whether the parties enlist any types of means to carry out their cooperation activities. Regarding the latter, we use a threefold distinction, differentiating between exchange of information, exchange of people (including study visits, joint research, seminars), and capacity building (including technical assistance). In total, we code 13 items under Institution.

All in all, our LABPTA coding scheme consists of 140 items pertaining to six main categories against which we have coded 487 PTAs signed between 1990 and 2015. The remaining parts of this paper will document key trends in the incidence and the design of LPs in PTAs over time.

\section{Trends in the content of LPs in PTAs, 1990-2015}

\subsection{The rise of LPs in PTAs}

The past 50 years not only witnessed a rapid proliferation in the number of PTAs, but also the gradual deepening of those agreements (e.g., Dür and Elsig, 2015). The same trend can be observed when assessing LPs in PTAs. Looking at the share of PTAs with LPs in the total number of PTAs signed in a given year, the data indicates that compared to an average of $32 \%$ in the 1990 s, the share rose to $40 \%$ during the first decade of the 2000 s, reaching an average of $61 \%$ during the period of 2010-2015 (with a peak of $80 \%$ in 2013) (Figure 1). 
Figure 1. Share of PTAs with LPs in total PTAs per year

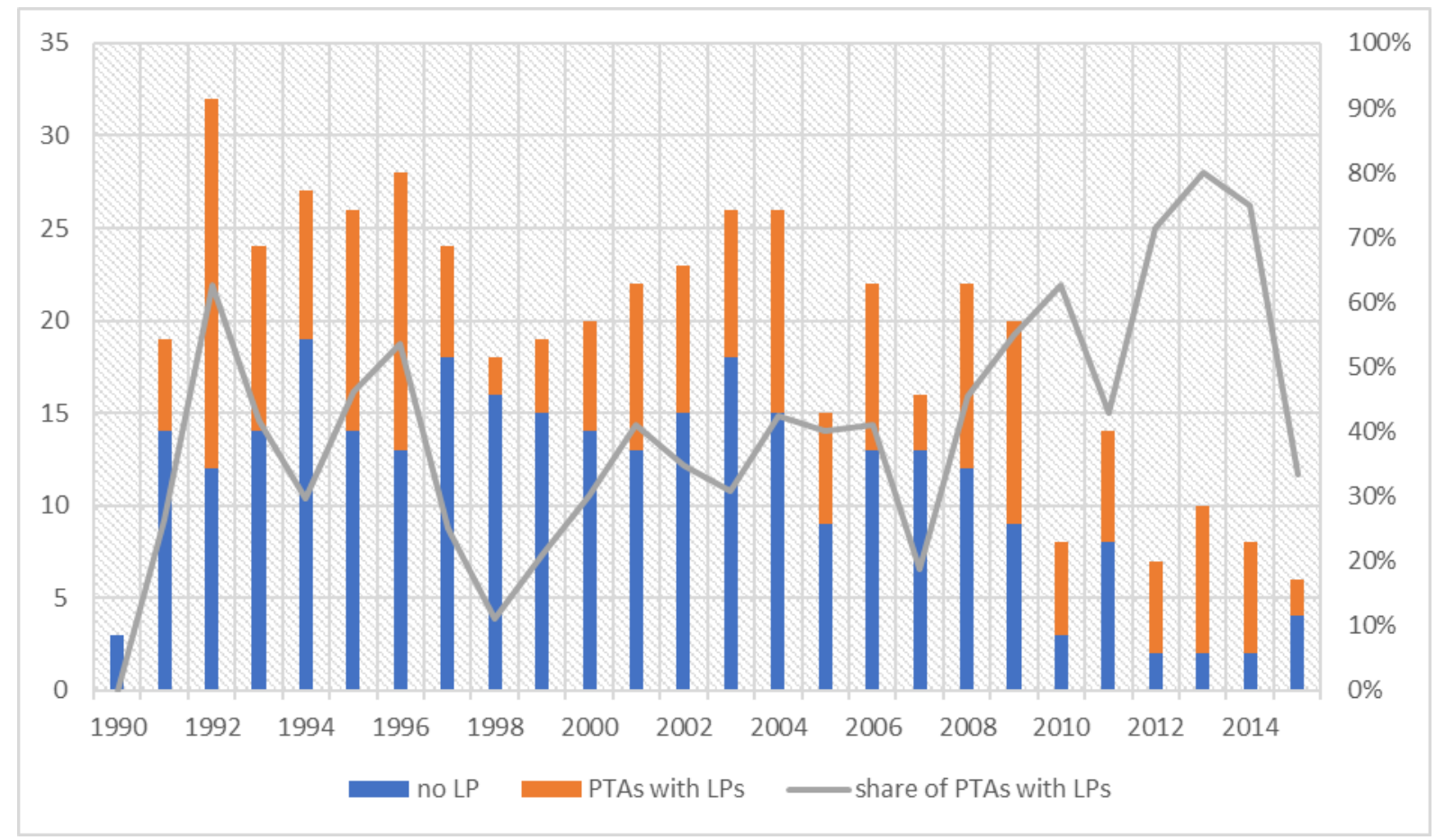

Note: PTAs with LPs include all agreements with at least one LP. The bars indicate the number of newly signed PTA with and without LPs per year.

Such an increase is rather surprising given the failure to adopt a social clause during the multilateral trade negotiations in the 1990s due to the opposition of developing countries. Until that point the only provision relevant to workers' rights was an exception to trade obligations for measures relating to products of prison labor under the General Agreement on Tariffs and Trade (Art. XX (e)), allowing prohibitions on imports of goods made by such labor.

The past two decades did not only present an increase in the number of PTAs including LPs in some form, but there has also been a rise in the adoption of PTAs with comprehensive LPs. While the total (cumulative) number of PTAs without or only with shallow LPs still surpasses the number of PTAs with comprehensive LPs, a steady increase in the pace of adoption of such PTAs can be observed in conjunction with the plateauing of shallow (and no LP) PTAs (Figure 2). In 2009, for the first time, more PTAs with LPs were adopted than PTAs without LPs, a trend that continued in subsequent years (with the exception of 2011 and 2015). Moreover, since 2006 trade partners have also predominantly opted for the adoption of PTAs with comprehensive LPs rather than shallow LPs (again with the exception of 2011 and 2015). 
Figure 2. Cumulative number of PTAs with no LP, shallow LPs, and comprehensive LPs

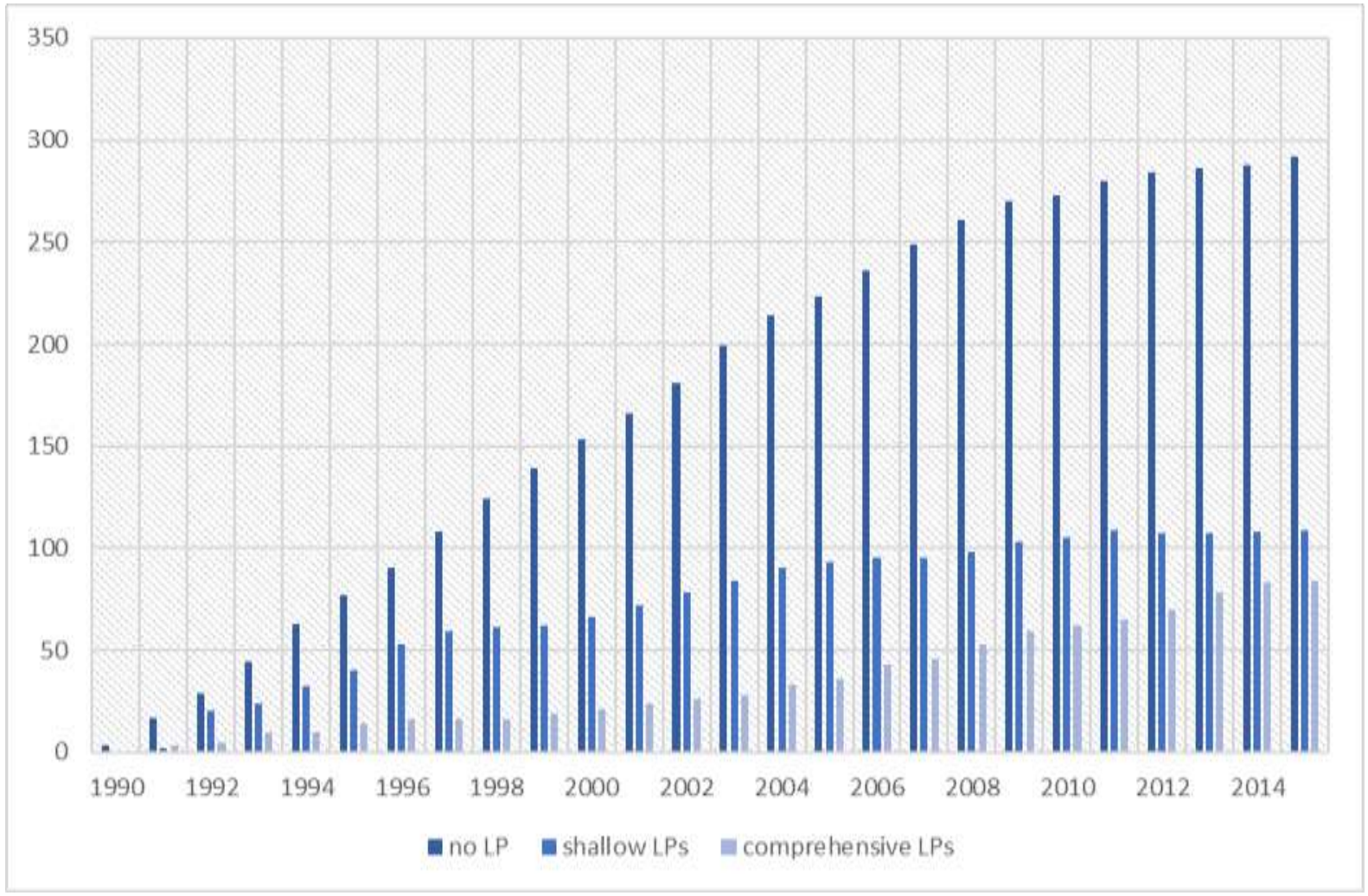

Breaking down PTAs by the level of development of its members and by broad types of LPs,${ }^{11}$ the data shows that the highest share of PTAs with any kind of LPs are signed between countries from the North while the highest share of PTAs with comprehensive LPs are signed between countries from the North and the South, highlighting potential protectionist motivations, but also genuine concerns for worker protection, by Northern countries in the introduction of LPs in North-South PTAs (Figure 3.A). In contrast, the majority of PTAs without any LPs are signed among countries in the South, having also the smallest share of agreements signed with comprehensive LPs. Interestingly, North-North PTAs have the largest share of PTAs with shallow LPs, followed by North-South and SouthSouth PTAs (Figure 3.B).

Figure 3. Distribution of PTAs by level of development of its members and broad types of trade-labor linkages (cumulated over 1990-2015)
A. By broad types of LPs
B. By level of development 

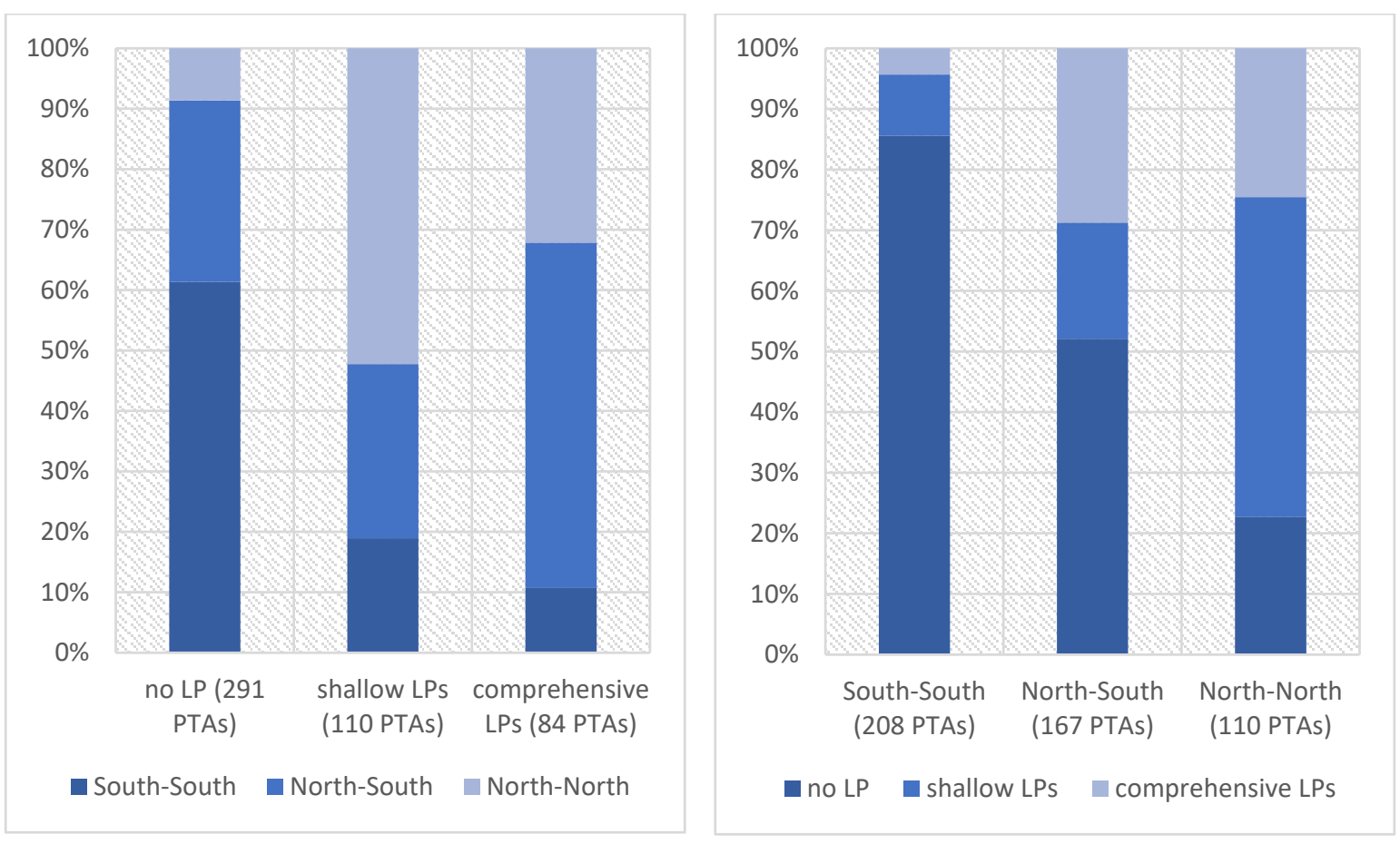

Exploring the data disaggregated by regions, the highest average number of PTAs with LPs are signed by Developed Economies and the members of the EU, ${ }^{12}$ followed by countries in Latin America and the Caribbean and then, surprisingly, countries in SubSaharan Africa (Figure 4). Despite the recent surge in PTAs - having tripled over the period of a single decade (Asian Development Bank, 2013) - Asia continues to fall behind other regions. Focusing on PTAs with comprehensive LPs, however, the East- and South-East Asia together with the Pacific region performs better than the Middle East and North Africa or the (non-EU) Central and South-Easter European and Commonwealth of Independent States, irrespective that such regions in total have more PTAs with LPs. This is, in part, explained by the comparatively late engagement with LPs in the region, resulting in a 'jump' of the generation of PTAs in which LPs are predominantly addressed in the preamble.

Figure 4. Average number of PTAs with LPs by region 


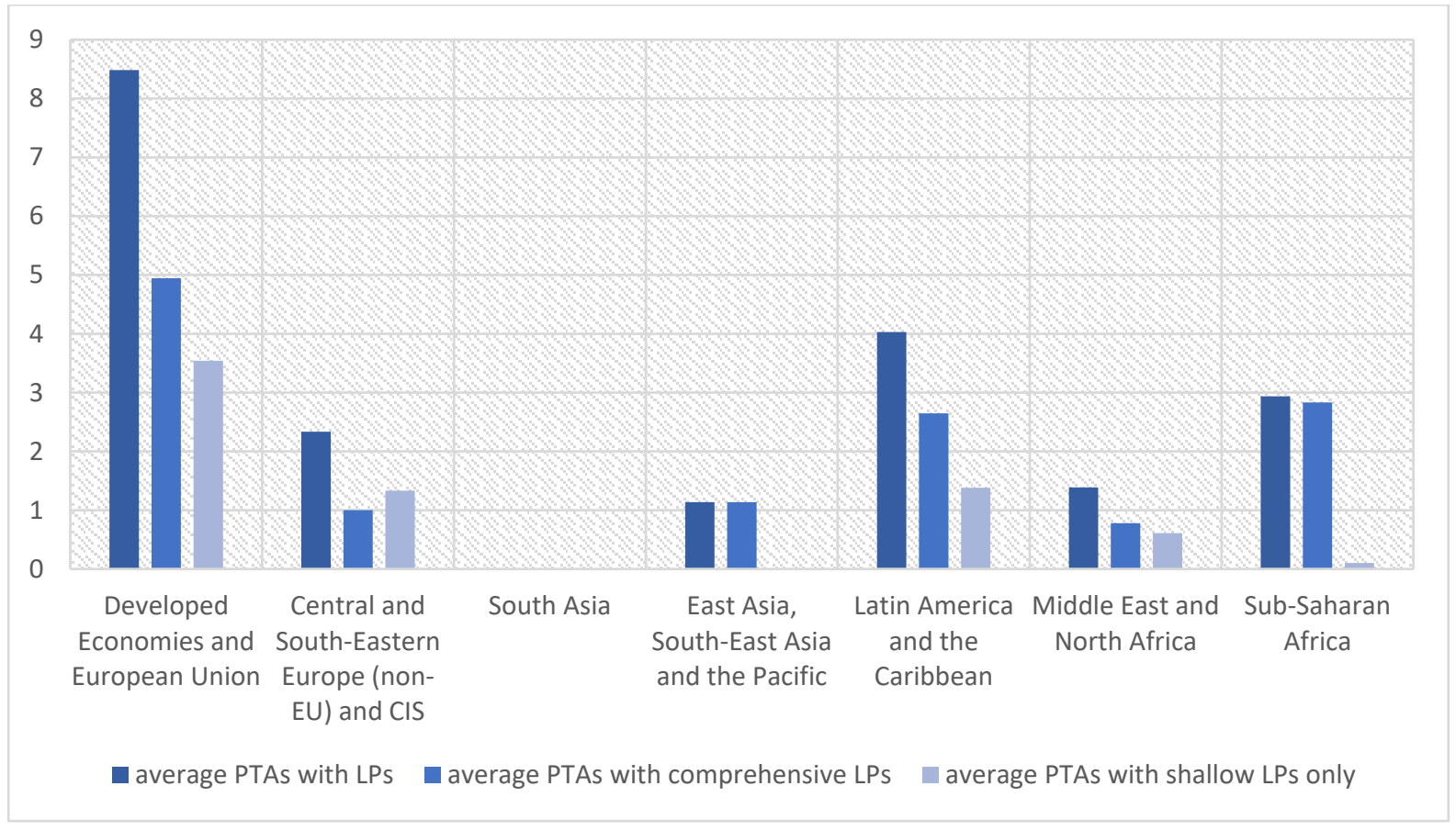

Note: The disaggregation follows the classification of the ILO (2014)

Delving into country-level data (Figure 5), the countries with the highest number of PTAs with LPs over 1990-2015 are the EFTA member states, followed by the EU-15 (i.e., countries that joined the EU pre-2004), and the Eastern European countries that joined the EU in 2004 (i.e., EU-10 countries). Among the countries with the highest number of PTAs with LPs are also the US, Canada and New Zealand, while from the South are Latin American countries, such as Chile, Peru and Colombia. Regarding the number of PTAs with comprehensive LPs (figure not shown), the picture is different: countries topping the list are the EU-15, followed by the US, the EU-10 , Chile, Canada, South Korea, Colombia and New Zealand, with the EFTA member states only afterward. It is worth noting that the results are in part driven by the numerous agreements signed between EU member states and prospective candidate countries prior to their accession to the Union.

Figure 5. Number of PTAs with LPs by country 


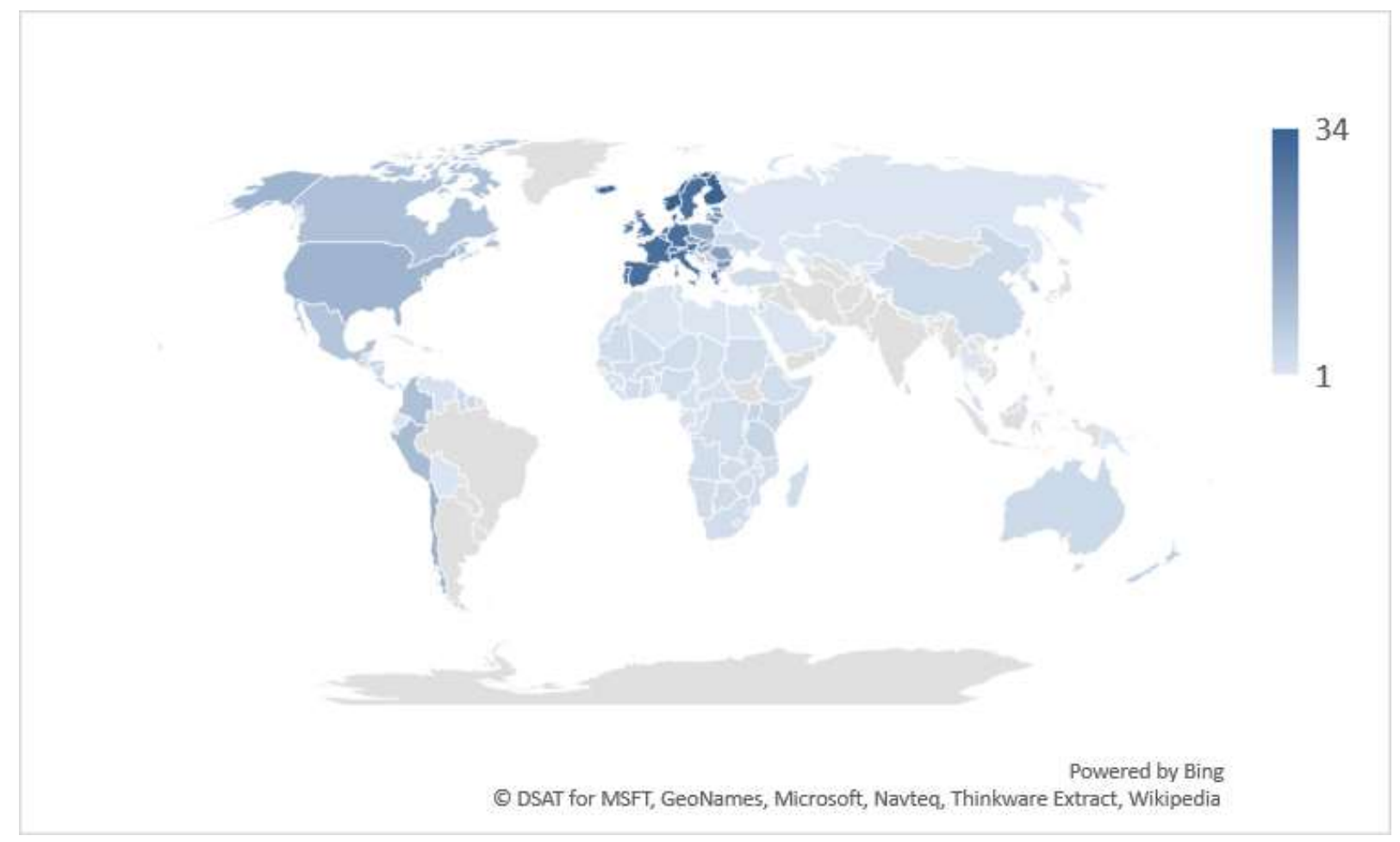

Note: The grey color in the map denotes countries that have not yet signed any PTA with LPs. To maintain the color distinction between countries that have not yet signed any PTA with LPs and countries that have signed PTA(s) with LP(s) the system takes the lowest value for countries that signed a PTA with $\mathrm{LP}(\mathrm{s})$ as the minim value for the scaling (i.e., 1).

When considering the average number of LPs across all PTAs signed by a given country over 1990-2015, the picture is different (Figure 6). As the map shows, the countries with the highest averages include the US and Canada (together with Georgia and Taiwan), followed predominantly by Latin American countries (Dominican Republic, Nicaragua, Honduras, Panama, El Salvador and Colombia), South-Korea and the EU-10. While much of this is determined by the combination of the extent of 'PTA activism' and the time countries start to engage with PTAs with LPs, one can nevertheless see that North American countries exceed the EU when it comes to the average number of LPs in their respective PTAs.

Figure 6. Average PSOECI score across all PTAs per country 


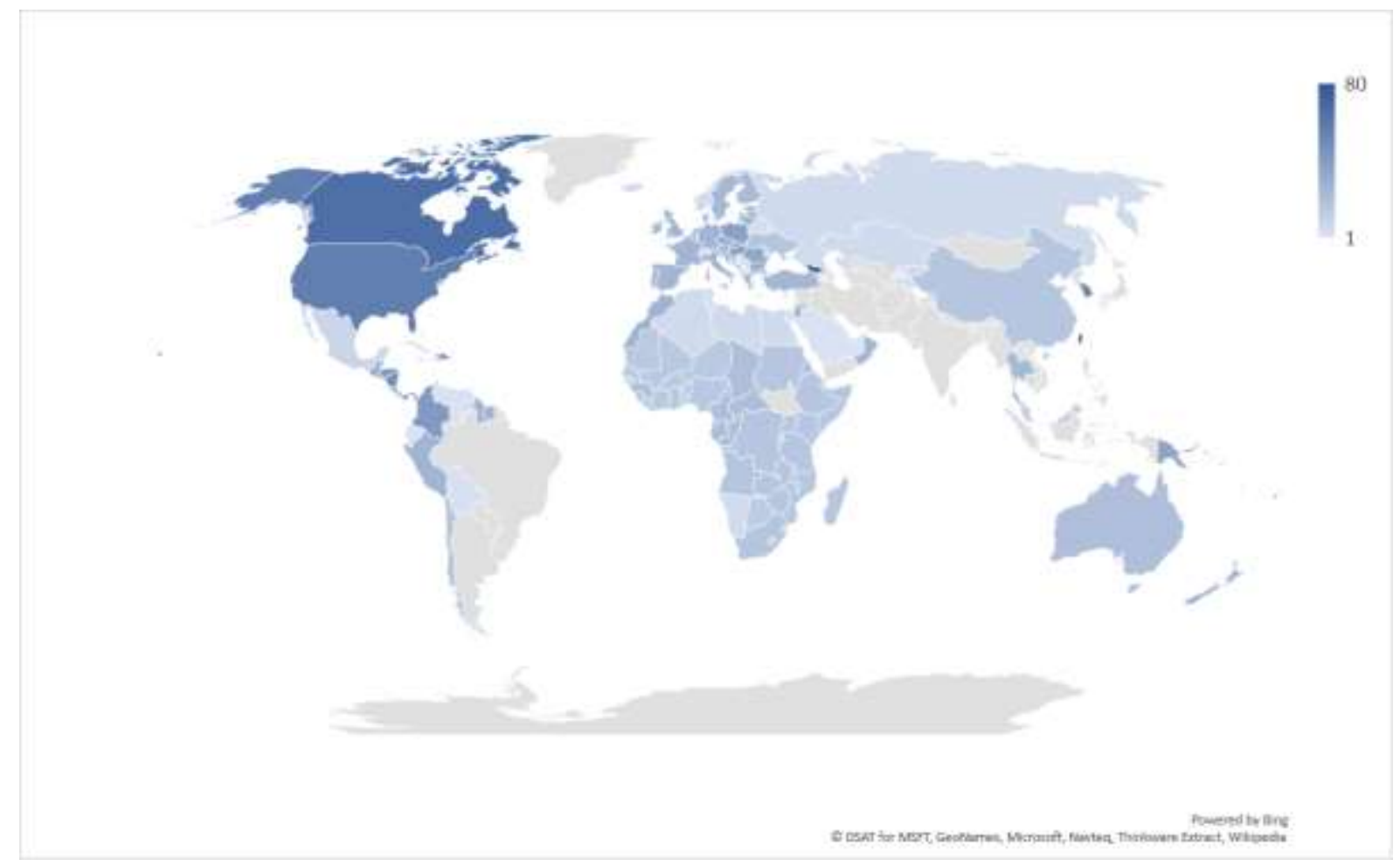

Note: see Figure 5.

\subsection{Types of LPs in PTAs}

Looking at the types of provisions included in PTAs with comprehensive LPs over the period of 1990-2015, on average most provisions concern the institutional framework set up for the monitoring and implementation of LPs in PTAs. This is closely followed by provisions concerning substantive commitments and those concerning cooperation commitments. However, only about half of the substance-related commitments are formulated as obligations and even fewer are enforceable through at least one of the three coded DSMs (Figure 7).

Figure 7. Average number of provisions per main category 


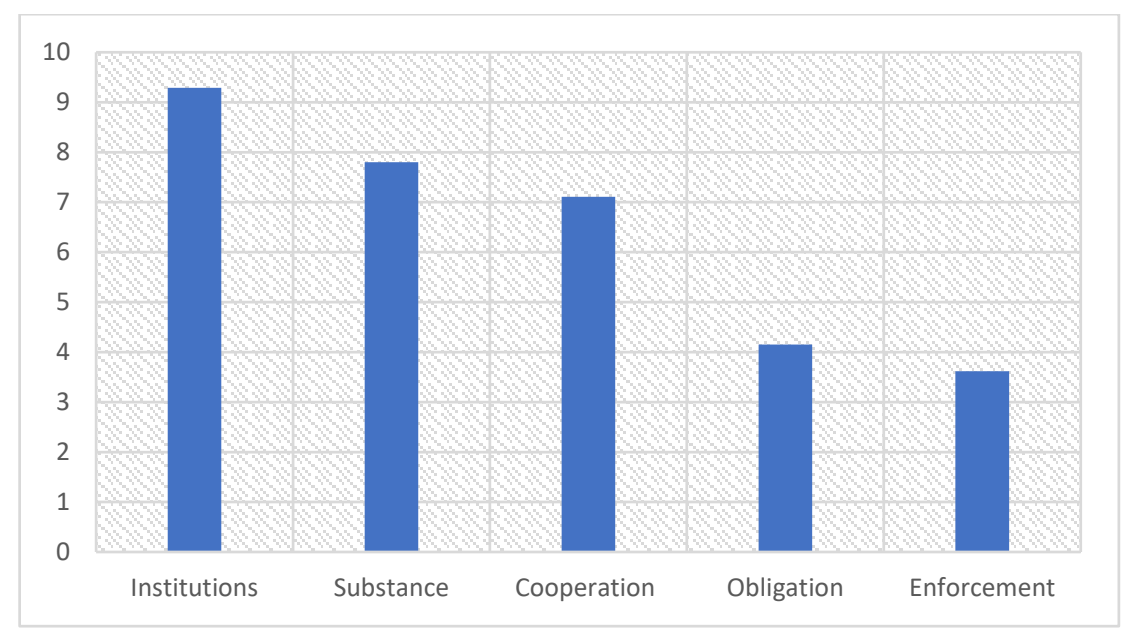

Note: the average number of provisions per category was calculated based on the sum of all items coded under a given category of LPs per PTA and averaged across all PTAs with comprehensive LPs. To balance out the fact that different categories have different number of items coded under it (see above), we weighted the average number of provisions per category against a total of 21 , the number of items listed under $\mathrm{C}$.

As to the change in the share of PTAs with a given LP type in the total number of signed PTAs for five- to six-year windows, the largest increase between the first (1990-1995) and the last (2011-2015) window took place in relation to the adoption of institution-related LPs (39 percentage points, from $3.1 \%$ to $42.2 \%$; Figure 8.F). This is closely followed not only by the increase in the share of PTAs with substance-related LPs (38.3 percentage point increase over the same time frame, from $8.4 \%$ to $46.7 \%$; Figure $8 . \mathrm{B}$ ), but also, at a very similar rate, the share of PTAs with obligatory commitments (37.7 percentage points, from $2.3 \%$ to $40 \%$; Figure 8.C) and enforceable commitments (36.1 percentage points, from $8.4 \%$ to $44.4 \%$; Figure 8.D), indicating a shift in the core design of LPs with an increasing emphasis on the bindingness and accountability of such commitments.

Figure 8. Share of LP types in total PTAs per five-year windows
A. Share of PTAs with Preambular LPs
B. Share of PTAs with Substance LPs 


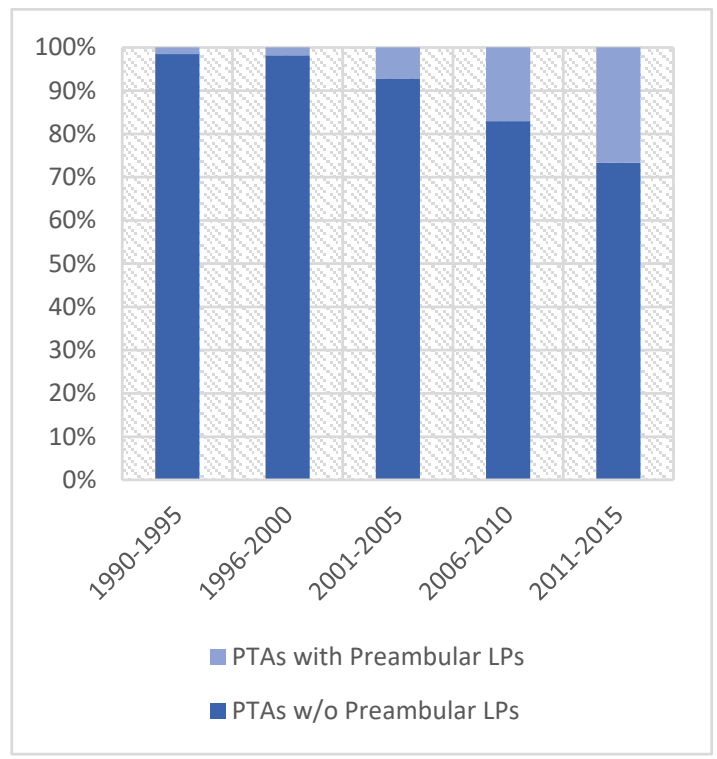

C. Share of PTAs with Obligation LPs

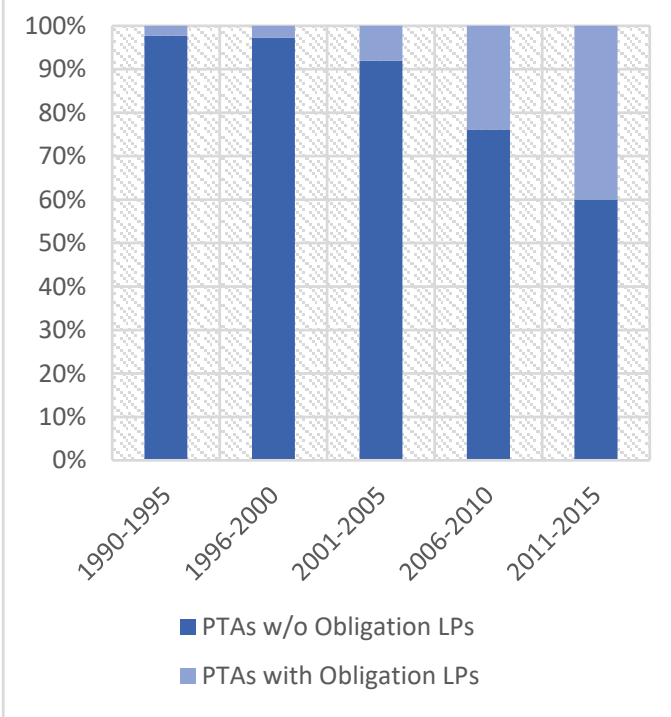

E. Share of PTAs with Cooperation LPs

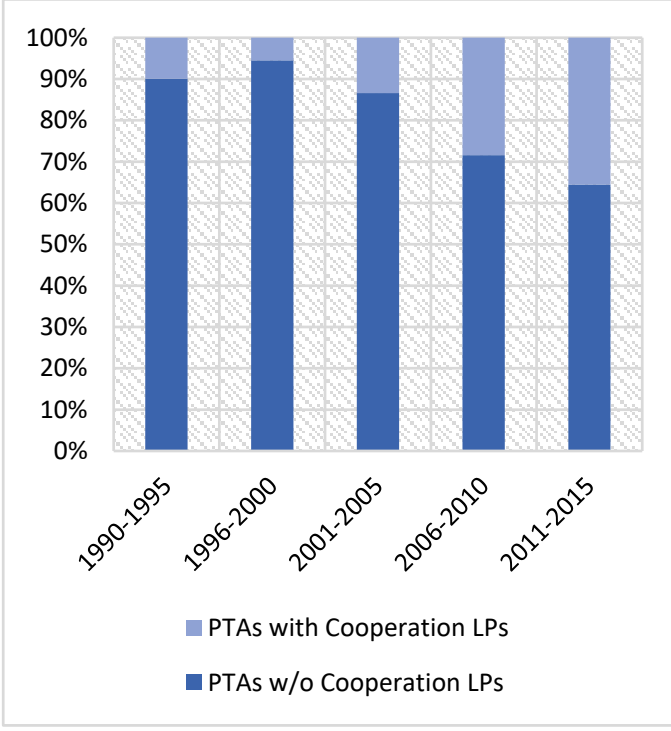

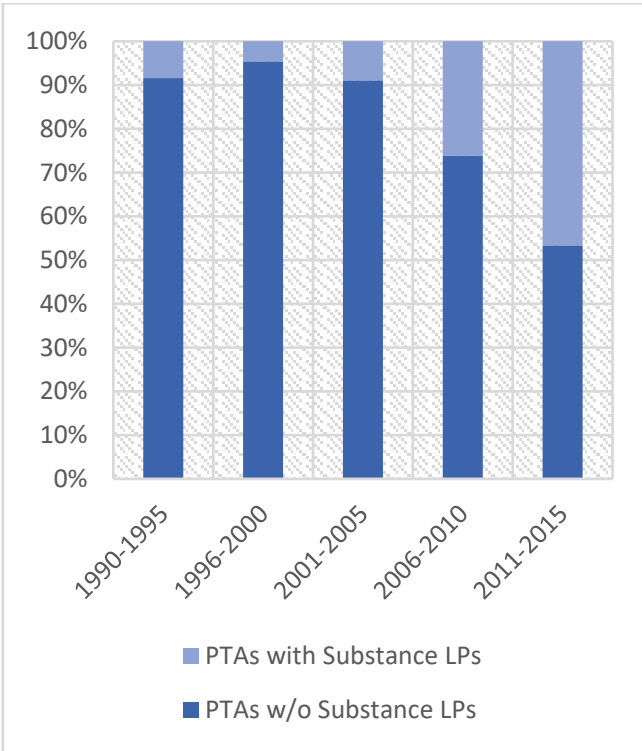

D. Share of PTAs with Enforcement LPs

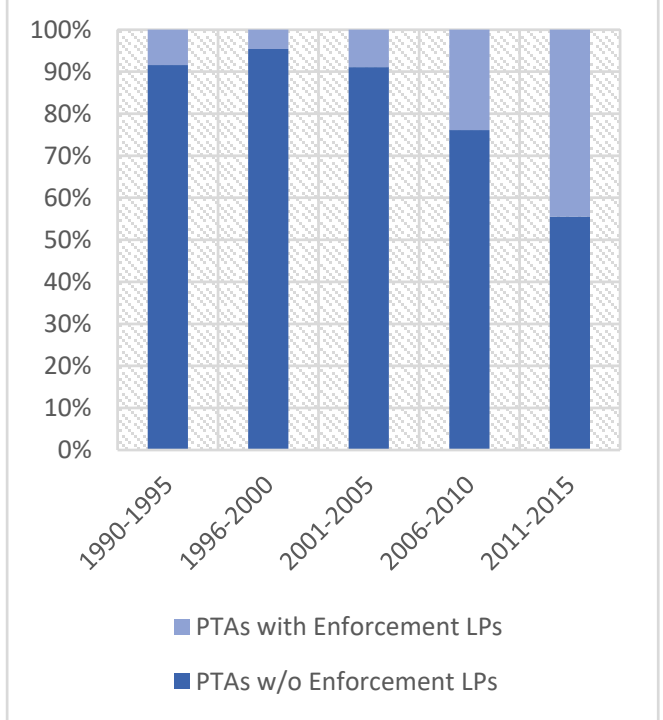

F. Share of PTAs with Institution LPs

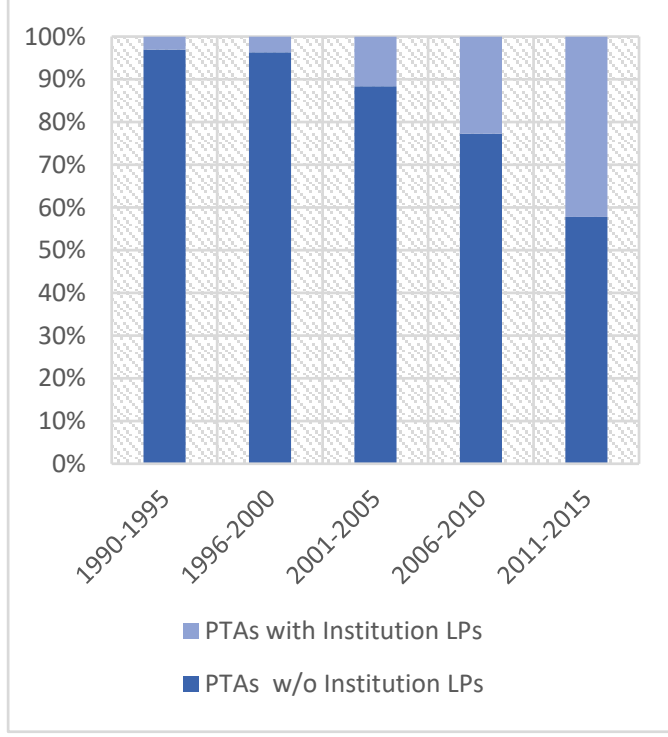


Although on average cooperation-related provisions are among the most frequently agreed commitments, comparatively speaking, a lower increase took place in the share of PTAs with cooperation-related LPs (25.6 percentage points between 1990-1995 and 20112015, from $9.9 \%$ to $35.6 \%$; Figure 8 .E). This can be partly explained by the more frequent and early use of such provisions in the EU PTAs signed with post-communist Eastern European States.

A closer examination of the substance- and cooperation-related commitments reveals that signatory parties have a different approach in the areas they wish to cover by such provisions. Substance-related commitments are dominated by the ILO 1998 Declaration and the related principles and rights on freedom of association and collective bargaining, the elimination of forced labor, the abolition of child labor and the elimination of discrimination in respect of employment and occupation (Figure 9.A). However, the provisions trade partners most frequently commit to relate to domestic law commitments, namely the effective enforcement of their laws and non-derogation. Under cooperation, the key focus - besides the most frequently noted health and safety commitments - is the improvement of the existing framework and practice of social dialogue and the strengthening of the labor administration and the inspection system (Figure 9.B).

Regarding the distribution of the three types of DSMs, on average the use of political DSM is still agreed two times more often than the arbitration based quasi-judicial DSM (Figure 10). Resorting to judicial DSM remains a rare feature of PTAs and mainly of those that besides regulating trade relations also establish a broader economic area (African Economic Community 1991, European Economic Area 1992, East African Community 1999) or common market (East African Common Market 2009). In a similar vein, the remedies that require consensus among the parties are the ones most frequently included in PTAs (46\% of all PTAs with comprehensive LPs) while the unilateral retaliation measures 'other appropriate measures', monetary compensation, and trade sanctions are agreed in fewer PTAs (36\%, 24\% and $17 \%$ of all PTAs with comprehensive LPs, respectively).

Figure 9. Frequency of substance- and cooperation-related issues
A. Substance-related issues
B. Issues covered by cooperation 

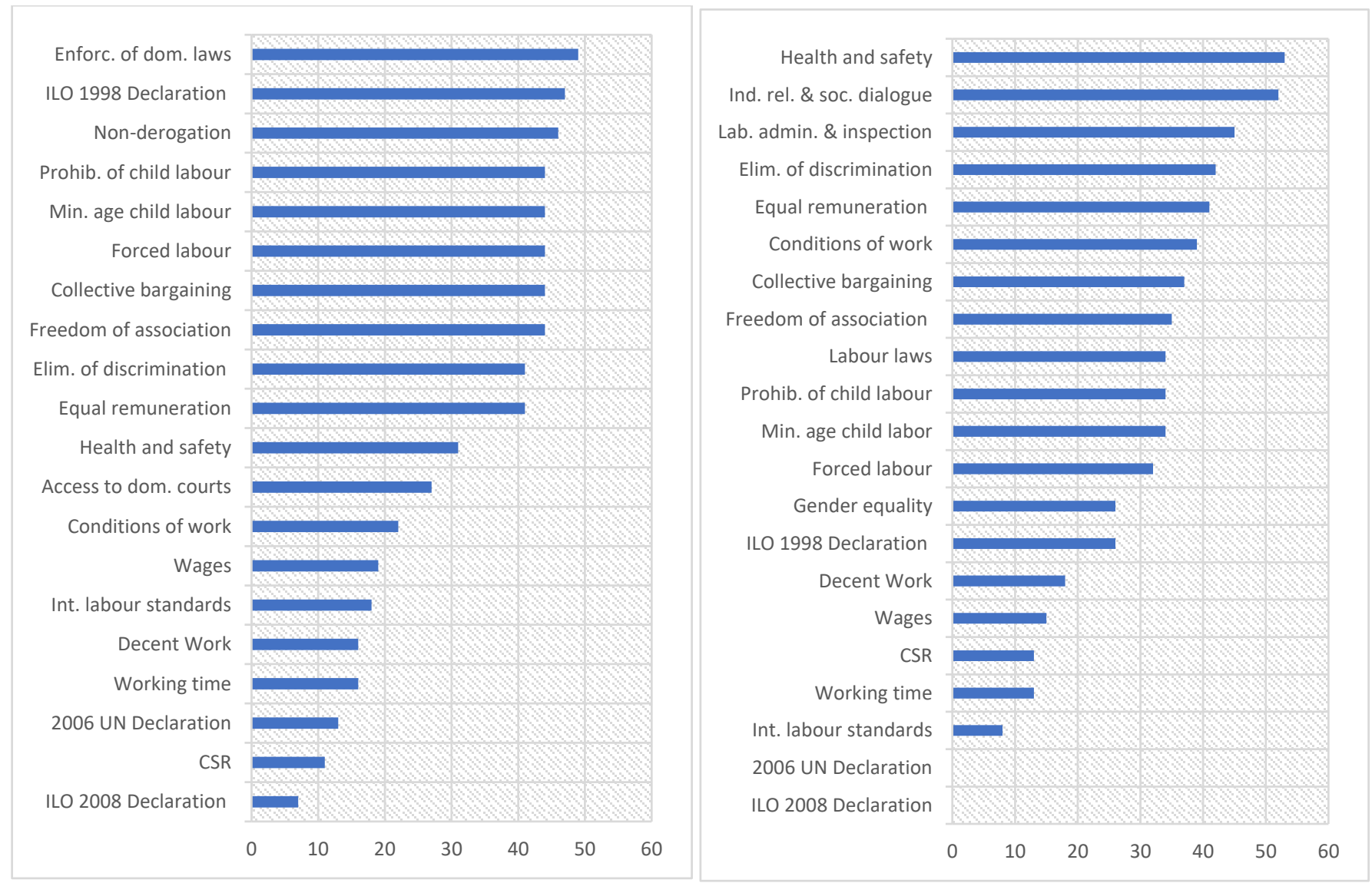

Figure 10. Average number of provisions relating to dispute settlement mechanisms

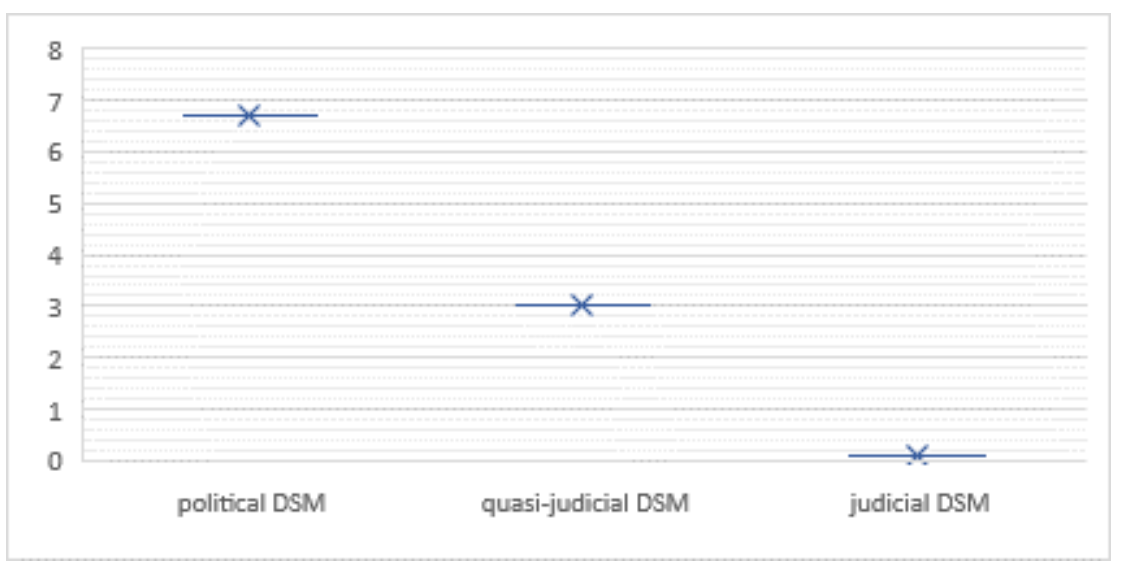

Note: the average number of provisions was calculated based on the sum of all items coded under political, quasi-judicial and judicial DSM per PTA and averaged across all PTAs with comprehensive LPs.

As discussed earlier, one significant change has been the rise of institution-related provisions. An interesting development in this regard is the increase in the involvement of third parties (social partners, ILO, NGOs, other third parties) (Figure 11). The inclusion of 
social partners and other third parties have progressively been recognized as an important element in the monitoring and implementation of LPs in PTAs - especially with the adoption of the EU's last generation of PTAs starting with EU - South Korea (2010). The participation of third parties has either been institutionalized through the establishment of an external permanent committees, such as the National Advisory Committee for Labor Provisions of US Free Trade Agreements operating under the US Department of Labor, or through mechanisms established within the PTA, such as the EU's Domestic Advisory Groups and the Civil Society Forum. The majority of references concern 'other third parties', closely followed by social partners and then NGOs. While the Singapore Ministerial Declaration (1996) designated the ILO as the competent body to deal with international labor standards in the context of international trade, reference to the ILO remains the least frequently mentioned provision and primarily relates to cooperation activities. Only in few cases may the parties seek advice from the ILO: no such role is granted to the ILO in US PTAs, while in Canadian PTAs the involvement of the ILO is limited to the panel selection procedures. It is only in the recently signed EU PTAs that the parties may seek advice of the ILO for the resolution of their disputes.

Figure 11. Number of PTAs with third party involvement under institutions per five-year windows

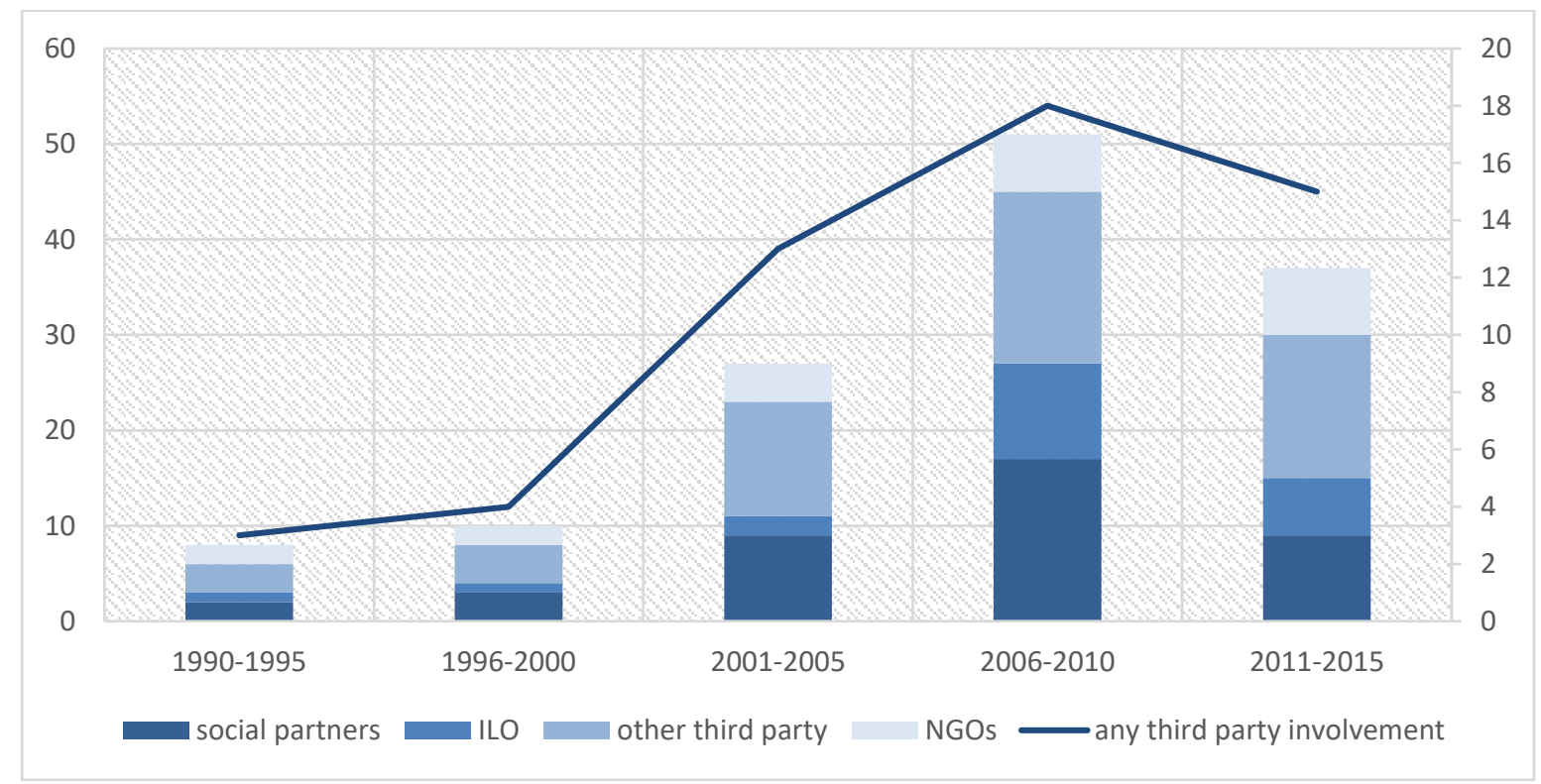

Note: The secondary axis depicts the number of PTAs with reference to any third party inclusion over the five-year windows. 


\subsection{Stringency of LPs in PTAs}

To further document the increase in the stringency of LPs over time, we develop two new measures, one for each of our two dimensions of stringency: strong enforcement and deep institutional LPs. Strong enforcement is defined through the simultaneous coding of quasi-judicial or judicial DSM and any of the following three unilateral sanctions: other appropriate measures, monetary compensation or trade sanctions. Deep institution is defined as the combination of a separate body established specifically for the monitoring and implementation of LPs and the inclusiveness of the institutional mechanism, that is, the involvement of any third parties in the monitoring and implementation of the agreements. Looking at the share of such provisions in the total number of signed PTAs for each of the five windows, the data shows that the use of either of those concepts showed a more modest increase over time compared to provisions described earlier (Figure 12.A-B).

Figure 12. Share of PTAs with strong enforcement and deep institutions LPs in total PTAs per five-year windows

\section{A. Strong enforcement}

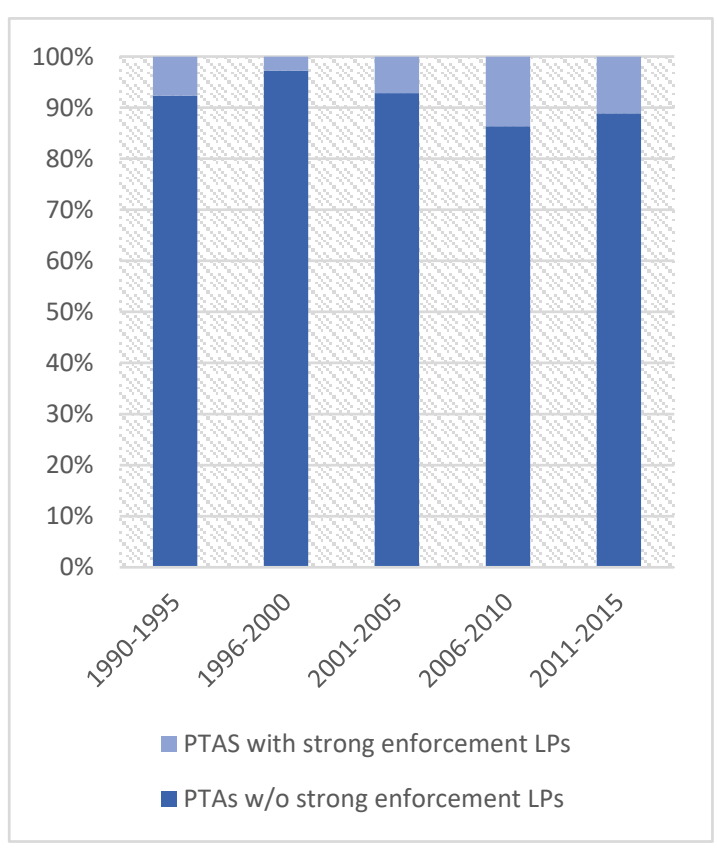

B. Deep institution

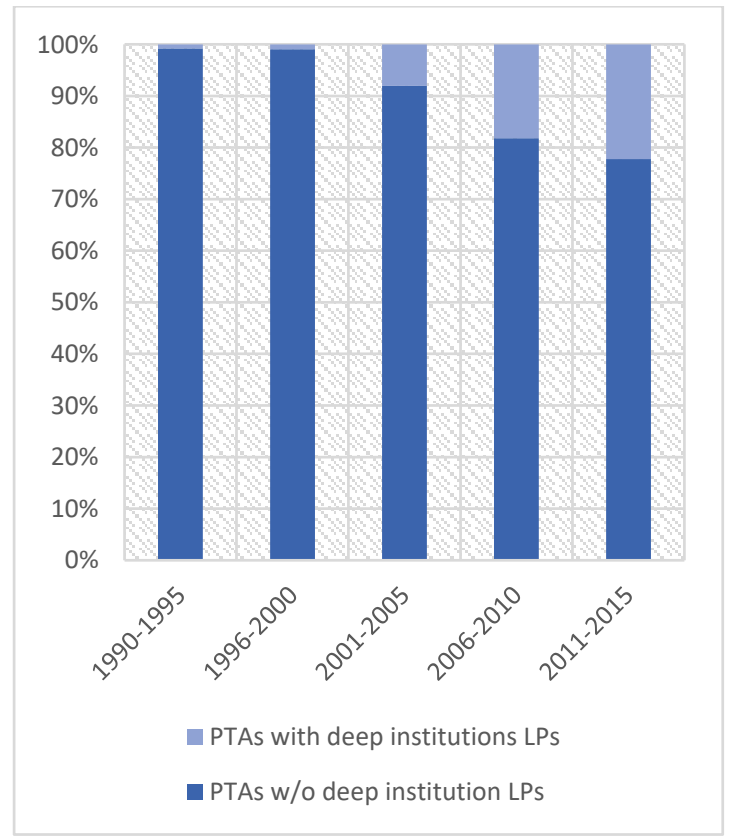

New provisions related to strong enforcement were more prevalent in the early $1990 \mathrm{~s}$ than those related to deep institutions, a trend that has reversed in recent years: while the deep institutional framework was not used during the 1990s, such provisions grew more rapidly 
than strong enforcement provisions from the early 2000s onwards (Figure 13.A). This variation is partly explained by the large number of PTAs signed by the EU with Central- and East-European countries in the 1990s, providing not only for arbitration-based DSM regarding - rather narrow types of - LPs, but also the possibility for the use of 'other appropriate measures' as sanctions in case of non-compliance. On the other hand, the US did not sign any PTA in the last five-year window, resulting in the lower number of PTAs with strong enforcement in that period. Regarding the distribution of such provisions by the level of development of PTAs members, the data indicates that the majority of PTAs with such provisions belong to the North-North and North-South agreements, while they continue to be a rather rare feature of South-South agreements (Figure 13.B). Interestingly, while strong enforcement is more often present in North-North PTAs compared to deep institutions, the opposite holds in South-South PTAs.

Figure 13. Strong enforcement and deep institutions
A. Rise over time
B. By type of level of development
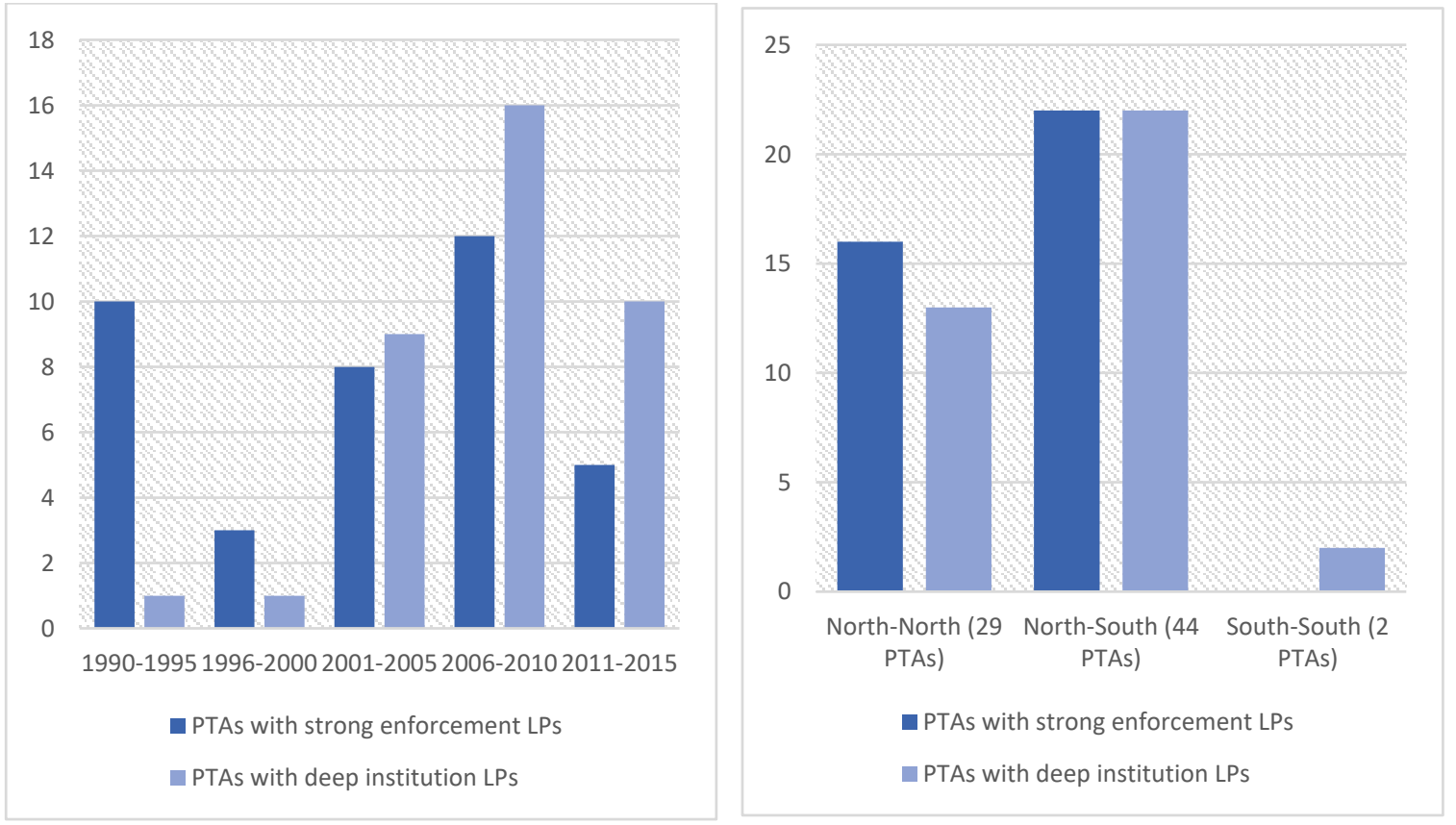

\subsection{LPs in PTAs by key players}

The actors that have largely shaped the design of LPs in PTAs are the US and the EU. As noted above, while the EU has since the early 1990s signed more PTAs with LPs than the US, on average the US continues to have a higher number of LPs included in its PTAs with comprehensive LPs (Figure 14). The trend has started to change with the introduction of the 
EU's last generation of PTAs in 2010 (Figure 14.A). ${ }^{13}$ Regarding the specific design, previous literature sums up the key differences by suggesting that the US uses a hard-law while the EU uses a soft-law approach. While it is true that the US applies overall a more stringent approach to LPs in PTAs, the difference between the two approaches are more subtle than previous studies indicated. On the one hand, obligation- and enforcement-related provisions are not absent from EU PTAs. On the other hand, US PTAs continue to include on average more cooperation-related provisions than EU PTAs (Figure 14.B). That said, with two exceptions (US-Jordan 2000 and US-Australia 2004), all US PTAs with LPs include the possibility to unilaterally impose both trade sanctions and monetary fines, whereas 'other appropriate measures' is the only available unilateral remedy in (some) EU PTAs.

Figure 14. LPs in US and EU signed PTAs

A. Average number of LPs per five-year windows B. Average number of LPs per main categories (cumulated over 1990-2015)
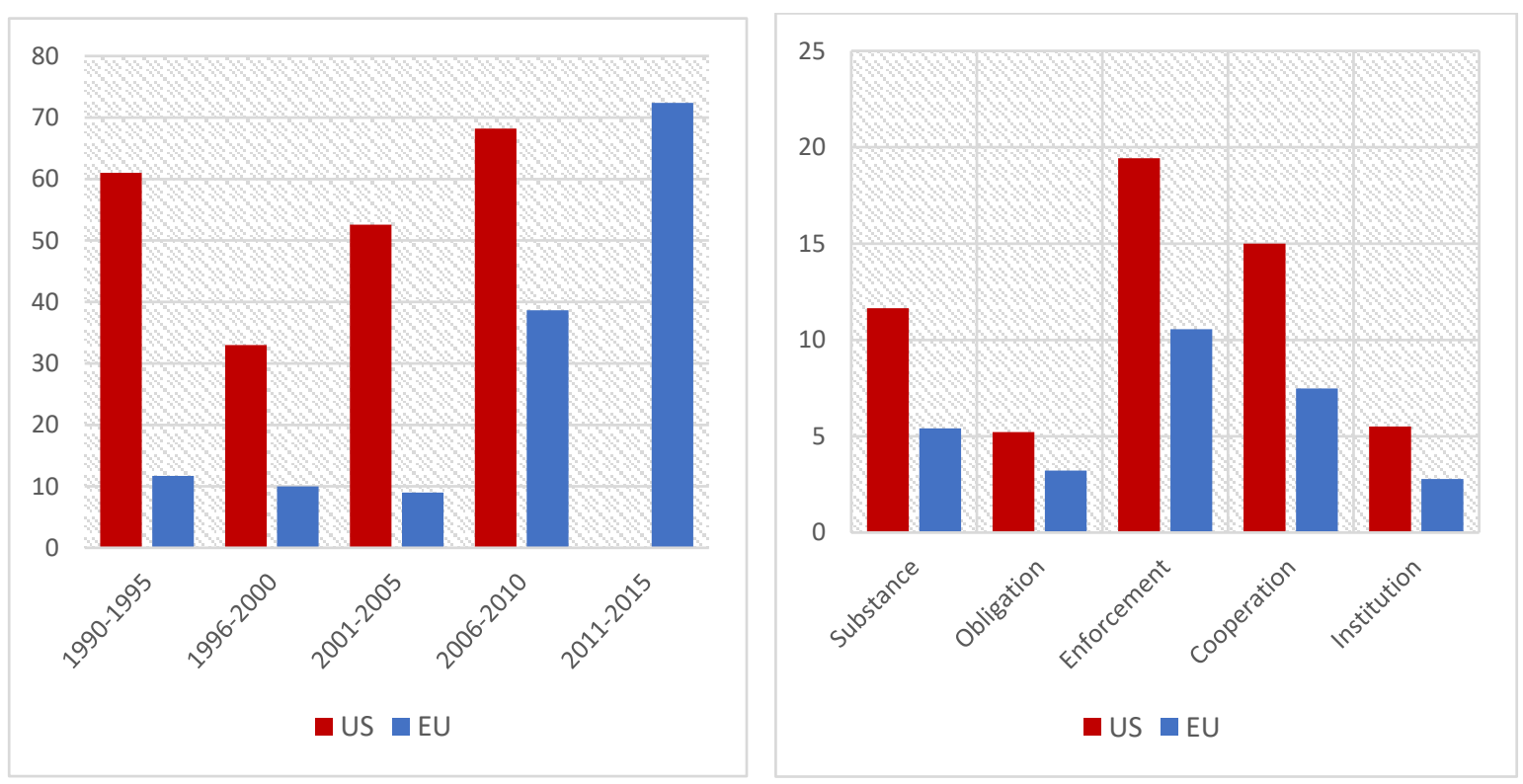

Canada and New Zealand, albeit the latter only since the early 2000s, also belong to the main drivers of the trade-labor linkage. Here a more pronounced difference can be identified: while Canadian PTAs with comprehensive LPs follow a stringent design for LPs with high averages both in terms of obligation/enforcement and cooperation-related provisions, such PTAs signed by New Zealand are shallower but they embody an idealtypical soft approach, more so than the EU, with predominantly non-binding and nonenforceable LPs (Figure 15.B). Interestingly, the types of provisions which do not show 
significant differences between the two countries are those related to the institutional framework. Comparing Canada with the EU or the US, however, the data shows that Canada has on average a higher number of LPs (especially with respect to substance, obligation and enforcement) (Figure 14-15). Canada's more progressive approach is also corroborated by its recent proposal of a more ambitious approach to advancing labor rights under the NAFTA renegotiations. ${ }^{14}$ One interesting aspect of Canadian PTAs with comprehensive LPs is that they only allow for monetary sanctions (with the exception of Canada-Costa Rica 2001) but not trade sanctions. ${ }^{15}$

Figure 15. LPs in PTAs signed by Canada and New Zealand
A. Average number of LPs per five-year windows
B. Average number of LPs per main categories (cumulated over 1990-2015)

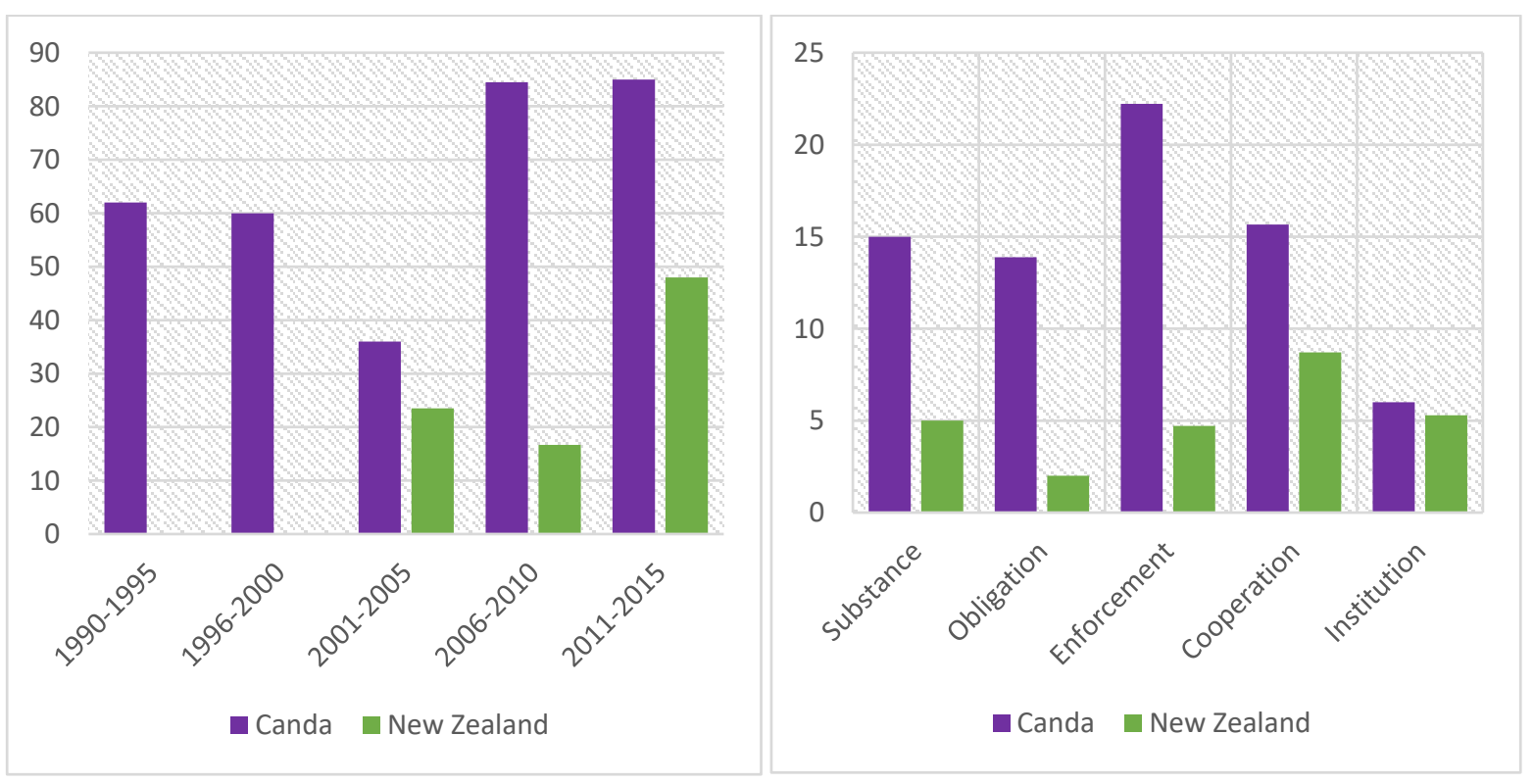

Regarding the stringency of LPs, as Figure 16 indicates the US and Canada negotiated LPs with strong enforcement provisions in all of their PTAs, and with deep institutions in all but one of their PTAs (US-Jordan 2000 and Canada-Costa Rica 2001). The EU offers a more varying picture with more PTAs including strong enforcement than deep institutions provisions. As noted above, this is mainly explained by the enforcement provisions included in PTAs signed during the 1990s with candidate countries, a design that is also found in some of the more recent EU PTAs (e.g., CARIFORUM-EC 2008). The increase in deep institutions relates mainly to the design of last generation agreements. By contrast, in the case of New Zealand, while none of the PTAs signed so far includes provisions pertaining to strong 
enforcement, almost all PTAs provide not only for a separate committee but also for the inclusion of third parties.

Figure 16. PTAs with strong enforcement and deep institutions, by key players

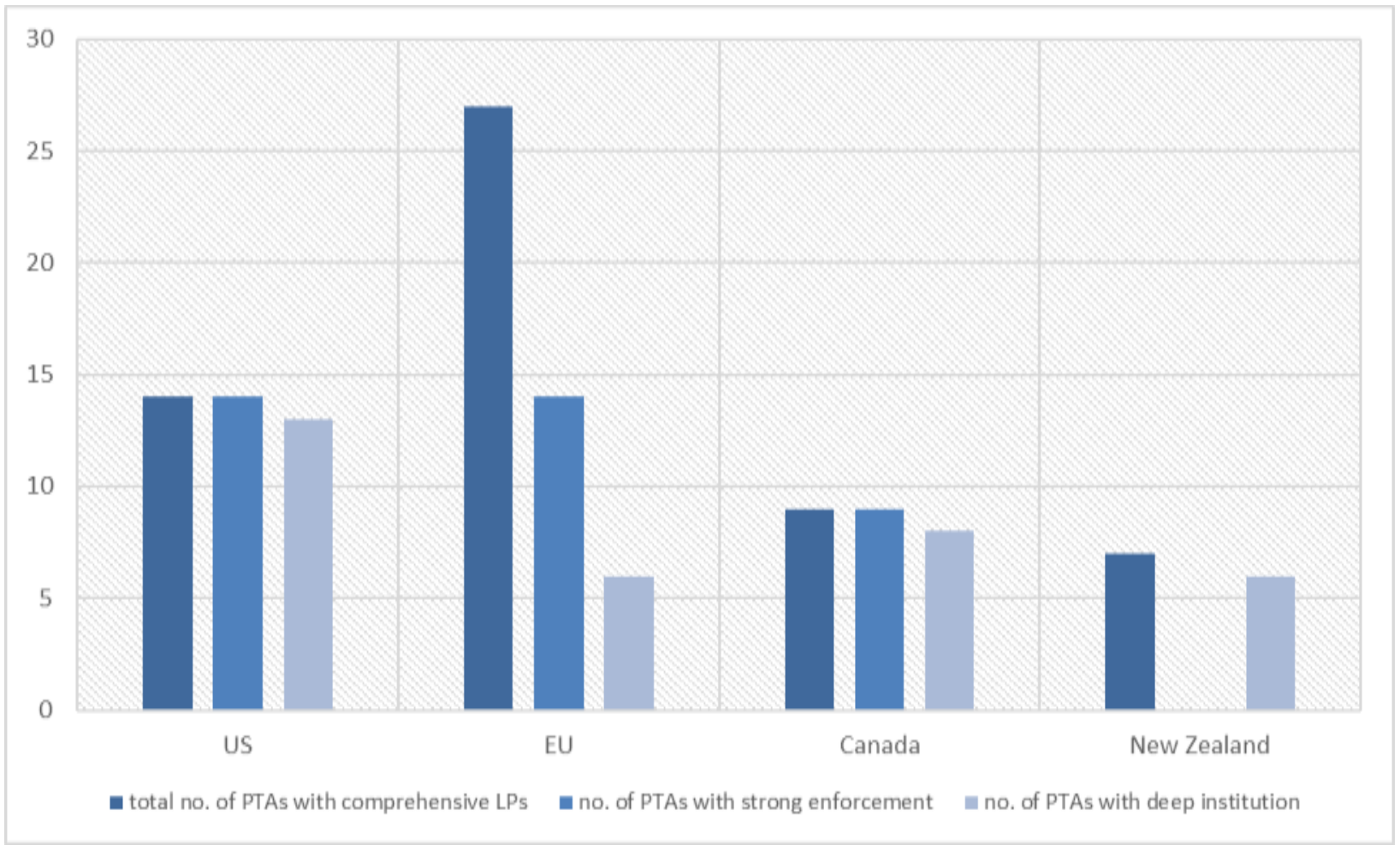

\subsection{LPs in South-South PTAs}

Throughout the past decades, and particularly since the early 2000s, countries from the South have also embarked on the introduction of LPs in the PTAs signed among themselves, although these agreements continue to remain rather limited in terms of their scope and stringency. ${ }^{16}$ The most noticeable increase in the average number of LPs took place during the last window (Figure 17.A) with the majority of those relating to cooperation or the institutional framework (Figure 17.B).

In terms of the stringency of PTAs with LPs signed between countries from the South, our coding shows that none of those agreements contain strong enforcement provisions and only 2 out of the 9 PTAs with comprehensive LPs provide for deep institutions (China-Peru 2009 and Colombia-Panama 2013) - leaving these agreements with LPs the least stringent ones. 
Figure 17. LPs in PTAs signed by countries from the South
A. Average number of LPs per-five-year windows
B. Average number of LPs per main categories (cumulated over 1990-2015)
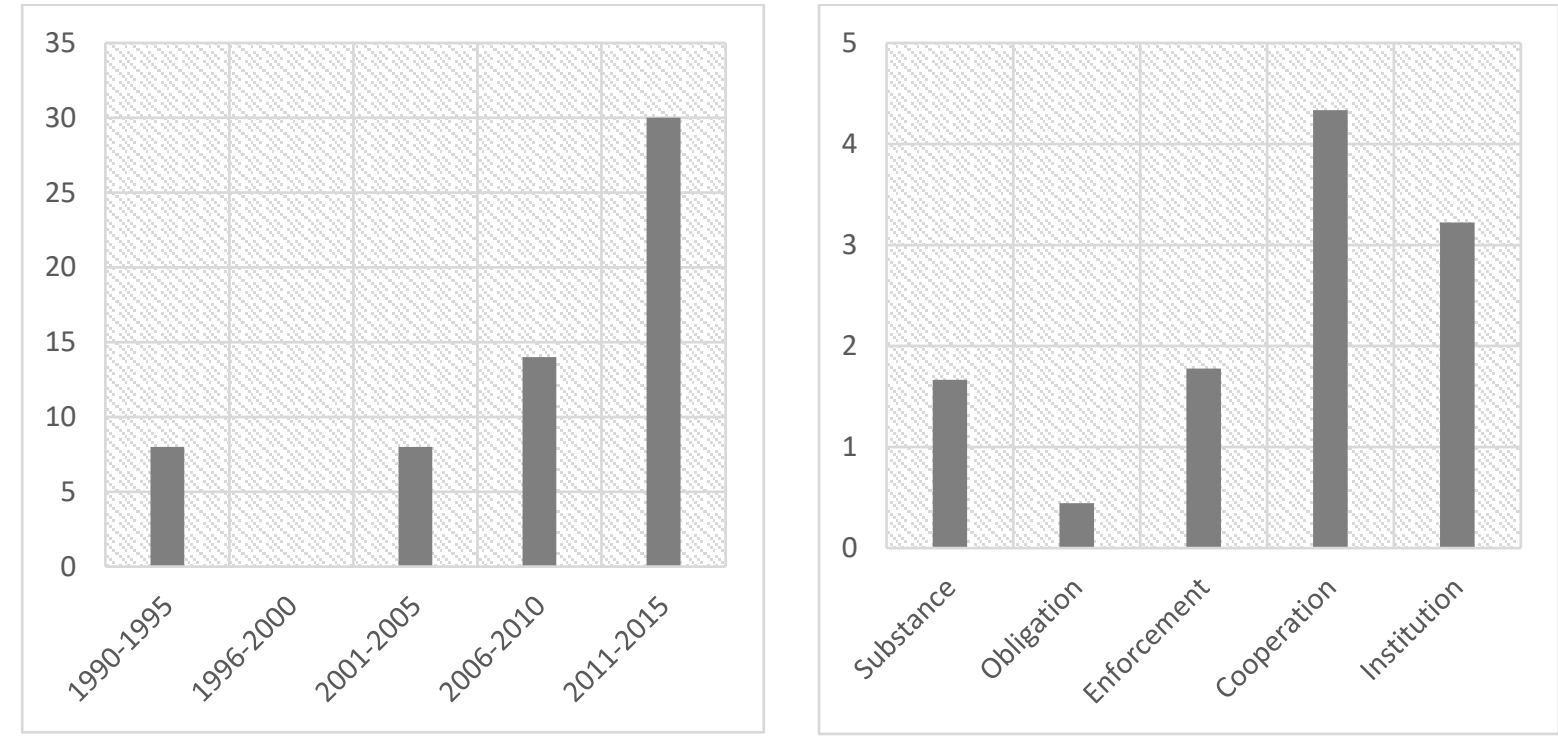

4.6. Comparing trends between LABPTA and other datasets

Considering conceptual differences, the comparative assessment across the various data remains limited. Importantly, among existing mappings, only the data constructed by Hofmann et al. (2017) is available. Regarding the period of 1990-2015, their dataset has 257 PTAs. Comparing LPs across the two datasets is challenging, especially for enforceability. The authors do not provide detailed coding manual and concepts used for the construction of the dataset, including what labor market provisions entail, are left without definitions. Enforceability is coded on a 0-2 scale with 1 if the language used in the PTA is sufficiently precise and committing and 2 if provisions concerned have not been excluded from DSM procedures under the PTA. A key drawback of their method is that it fails to explain what type of DSMs are considered for the coding and neglects the role of the different sanctions agreed upon by trade partners.

In any case, the two datasets point to similarities and differences in results. ${ }^{17}$ Out of the 257 PTAs, labor market regulation was coded in 67 PTAs (26\% of all PTAs). Taking PTAs with comprehensive LPs as the comparable measure, the share of PTAs with LPs is higher than under LABPTA (17\%). Looking at changes in the share of PTAs with labor market regulation in the total number of PTAs signed in a given year, the Hofmann et al. data shows a similar trend as described under Figure 1: compared to an average of $8 \%$ in the 
1990 s, the share rose to $26 \%$ during the first decade of the 2000 s, reaching an average of $52 \%$ during the period of 2010-2015 (with a peak of $86 \%$ in 2014). Regarding enforceability, out of the 67 PTAs, in 19 PTAs (28\%) LPs are legally enforceable but excluded from the DSM, while in 27 PTAs (40\%) LPs are legally enforceable and covered by DSM, indicating a similar degree of enforceability with LABPTA (22\% and 42\%, respectively, of all PTAs with comprehensive LPs; when equating Hofmann et al.'s variables of enforceability with LPs that are binding and subject only to political DSM, on the one hand, and LPs that are binding and subject only to quasi-judicial and/or judicial DSM, on the other hand). Looking at change over time, while under Hofmann et al. there is a decrease in the share of PTAs with provisions that are enforceable and covered by DSM (from 80\% during 1990-1995 to 20\% in 2011-2015), under LABPTA LPs that are binding and covered by quasi-judicial and/or judicial DSM are on the rise until 2010 (from 23\% during 1990-1995 to 54\% in 2006-2010) only after which there is a decrease (32\% in 2011-2015).

\section{$\underline{\text { 5. Conclusion }}$}

Discussions regarding the role and effectiveness of LPs have over the past decade intensified among scholars and practitioners, particularly with the negotiation of the now defunct (?) mega-regional trade agreements, such as the Trans-Pacific Partnership and the Transatlantic Traded and Investment Partnership. The primary goal of the paper was to introduce a brand new dataset on LPs in PTAs (LABPTA) and to offer a detailed and up-todate description of the design of existing provisions. By providing a fine-grained approach to the mapping of LPs in PTAs the dataset allows for a better assessment of the trade-labor nexus on a global scale both for researchers, policy makers and practitioners - a contribution that has become much timely with the 2017 US elections, the ongoing Brexit negotiations or even the possible renegotiation of previously signed PTAs.

Among the main findings derived from the descriptive analysis is a twofold trend: on the one hand, LPs in PTAs are in general becoming more stringent (with more binding and enforceable provisions) mainly as a result in the design adopted by key trade players such as the US, Canada and the EU; on the other hand, evidence also indicates for the continuation of less stringent provisions (with few binding and even fewer enforceable provisions), particularly by actors that more recently started to incorporate LPs in their trade agreements (i.e., New Zealand, EFTA or countries from the South signing PTAs among themselves). However, one key commonality is the increased emphasis put on the institutional framework 
responsible for the monitoring and implementation of LPs in PTAs, resulting - although to a different degree - in more inclusive and specialized institutions.

With the NAFTA renegotiations and the EU's renewed debate on Trade and Sustainable Development, the design of LPs in PTAs has yet again come to the fore. In both cases trade unions are pushing for the broadening of the scope of issues incorporated in PTAs and for more efficient, sanctions-based DSMs to 'facilitate transition to upward convergence to establish common ground for fair and just trade between countries' ${ }^{18}$ Such demands gained momentum in light of the ruling handed down in the US-Guatemala case where the dispute panel found that the litigants could not prove that the violations were trade-related and hence actionable under the agreement. Proposals are also made to move beyond the narrowly defined working conditions (e.g., working time, minimum wage) and to tie those commitments to internationally defined standards instead of committing countries to enforce their own national laws on those issues. In the European Commission's 15-point plan to make EU trade and sustainable development chapters more effective (February 2018), ${ }^{19}$ the EU committed to 'continue to include commitments on the effective occupational health and safety and labour inspection system in line with international standards', indicating a higher degree of commitment but without the actual expansion of the issues covered.

At the same time, with the expansion of countries agreeing to LPs in their PTAs, particularly those from the South (but also with the increasing convergence in the scope of LPs), the reintroduction of the trade-labor linkage in the WTO's agenda could be seen as a possible avenue for the future of labor governance through trade. Although in the 2001 Doha Ministerial Declaration ${ }^{20}$ the WTO reaffirmed its position adopted in Singapore, the growing references and commitments in PTAs to LPs might create space for the reopening of the discussion. While their might be arguments against putting LPs on the Doha Round's already intricate and slowly moving agenda, it might also provide a bargaining chip for developing countries to help break the deadlock of the Doha Round. Looking at the large emerging economies, China has already signed four PTAs with LPs (with Chile, New Zealand, Peru and Switzerland), while Brazil and India, who have not signed any PTAs with LPs, are currently both in negotiation with the EU and EFTA. Despite India being among the key countries objecting to the social clause during the 1990s, current available reports no longer indicate that the inclusion of LPs would constitute a remaining obstacle in the negotiations. The same holds for Brazil.

In choosing between existing designs, one of the key challenges faced by policy makers has been the limitations in quantitative research on the effectiveness of LPs. At the 
core of this has been the lack of available data on LPs in PTAs. While our hope is to fill this gap, limitations to our method should be acknowledged: on the one hand, the binary coding does not always allow for nuanced distinction between varying scopes of the same commitment across different PTAs; ${ }^{21}$ on the other hand, our scope-driven approach to DSM leaves out important procedural features that - as the US-Guatemala case presents - can be decisive in the settlement of labor-related disputes. Subject of future discussion is the possible weighting of our items, all of which is treated now as equally weighted. Finally, given that it is intrinsic to such provisions to evolve over time, inclusion of additional items both under scope and stringency might be warranted. 


\section{$\underline{\text { References }}$}

Abbott, K.W., Keohane, R. O., Moravcsik, A., Slaughter, A-M. and Snidal, D. (2000) 'The Concept of Legalization', International Organization, 54 (3), pp. 401-19.

Asian Development Bank (2013) Regional Cooperation and Integration in a Changing World. Mandaluyong City, Philippines: Asian Development Bank.

Bourgeois, J., Dawar, K. and Evenett, S.J. (2007) 'A Comparative Analysis of Selected Provisions in Free Trade Agreements', Commissioned by DG Trade [online]. Available from: http://trade.ec.europa.eu/doclib/docs/2008/march/tradoc 138103.pdf [Accessed 16 May 2018]

Chase, C., Yanovich, A., Crawford, J.-A. and Ugaz, P. (2016) 'Mapping of disputes settlement mechanisms in regional trade agreements - innovative or variations on a theme?', in R. Acharya (ed.), Regional Trade Agreements and the Multilateral Trading System. Cambridge: Cambridge University Press, pp. 608-702.

Dür, A. and Elsig, M. (eds) (2015) Trade Cooperation: The Purpose, Design and Effects of Preferential Trade Agreements. Cambridge: Cambridge University Press.

Dür, A., Baccini, L. and Elsig, M. (2014) 'The Design of International Trade Agreements: Introducing a New Dataset', Review of International Organizations, 9 (3), pp. 353-75.

Giumelli, F. and van Roozendaal, G. (2017) 'Trade agreements and labour standards' clauses: Explaining labour standards developments through a qualitative comparative analysis of US free trade agreements', Global Social Policy, 17 (1), pp. 38-61.

Hafner-Burton, E. (2009) Forced to Be Good. Why Trade Agreements Boost Human Rights. Ithaca: Cornell University Press.

Hofmann, C., Osnago, A. and Ruta, M. (2017) 'Horizontal Depth: A New Database on the Content of Preferential Trade Agreements', Policy Research Working Paper 7981, World Bank Group, Trade and Competitiveness Global Practice Group [online]. Available from: http://documents.worldbank.org/curated/en/700771487791538589/pdf/WPS7981.pdf [accessed 16 May 2018]

Horn, H., Mavroidis, P. C. and Sapir, A. (2010) 'Beyond the WTO? An Anatomy of EU and US Preferential Trade Agreements', The World Economy, 33, pp. 1565-88.

Hulme, M. H. (2016) 'Preambles in Treaty Interpretation', University of Pennsylvania Law Review, 164 (5), pp. 1281-1343.

International Labour Organization (2017) Handbook on Assessment of Labour Provisions in Trade and Investment Agreements. Geneva: ILO.

(2016) Assessment of Labour Provisions in Trade and Investment Arrangements. Geneva: ILO.

(2014) Global Employment Trends 2014: The risk of a jobless recovery. Geneva: ILO. (2013) Social Dimensions of Free Trade Agreements. Geneva: International Institute for Labour Studies, ILO. (2009) World of Work Report 2009: The Global Jobs Crisis and Beyond. Geneva: International Institute for Labour Studies, ILO.

Kamata, I. (2016) 'Labor Clauses in Regional Trade Agreements and Effects on Labor Conditions: An Empirical Analysis', IDE Discussion Paper No. 609, Institute of Developing Economies [online]. Available from: http://www.ide.go.jp/library/English/Publish/Download/Dp/pdf/609.pdf [Accessed 16 May 2018]

Kerremans, B. and Gistelinck, M.M. (2009) 'Interest Aggregation, Political Parties, Labour Standards and Trade: Differences in the US and EU Approaches to the Inclusion of 
Labour Standards in International Trade Agreements', European Foreign Affairs Review 14, pp. 683-701.

Lechner, L. (2016) 'The domestic battle over the design of non-trade issues in preferential trade agreements', Review of International Political Economy, 23 (5), pp. 840-71.

Milewicz, K.M. (2016) 'The Design of Trade Agreements (DESTA): Non-Trade Issues Codebook' [online]. Available from:

https://www.designoftradeagreements.org/media/filer_public/ef/35/ef351ccf-b6984e6e-b8e7-686a1becaf7d/nti_codebook.pdf [accessed 16 May 2018].

Milewicz, K., Hollway, J., Peacock, C. and Snidal, D. (2018) 'Beyond Trade: The Expanding Scope of the Non-Trade Agenda in Trade Agreements', Journal of Conflict Resolution, 62(4), pp. 743-73.

Nyland, C. and O'Rourke, A. (2005) 'The Australia-United States Free Trade Agreement and the Ratcheting-Up of Labour Standards: A Precedent Set and an Opportunity Missed', Journal of Industrial Relations, 47 (4), pp. 457-70.

Polanyi, K. (2001 [1944]) The Great Transformation: The Political and Economic Origins of Our Time. Boston: Beacon Press.

Postnikov, E. and Bastiaens, I. (2014) 'Does Dialogue Work? The Effectiveness of Labor Standards in EU Preferential Trade Agreements', Journal of European Public Policy, 21 (6), pp. 923-40. 
${ }^{1}$ PTAs are agreements liberalizing trade between two or more countries without extending this liberalization to all countries.

${ }^{2}$ Search keywords used are: labour, labor, employ, work, strike, social, ILO, right, disrim, health, capacity, training, education, equal, equality, poverty and safeguard.

${ }^{3}$ For example the Colombian Action Plan Related to Labor Rights (April 2011) adopted in relation to the U.S. Colombia Trade Promotion Agreement (2006).

${ }^{4}$ Horn et al. (2010) differentiate between coverage (or scope) and legal enforceability.

${ }^{5}$ Fundamental rigts refer to the principles and rights in four categories, as defined by the ILO Declaration on Fundamental Principles and Rights at Work adopted in 1998: freedom of association and the effective recognition of the right to collective bargaining; the elimination of forced or compulsory labor; the abolition of child labor; and the elimination of discrimination in respect of employment and occupation.

${ }^{6}$ We code provisions related to working conditions (generic category if the content of the conditions of work is unspecified), working time, wages, and health and safety.

${ }^{7}$ Although not defined in PTAs, reference to decent work encompasses the four pillars identified by the ILO as essential to the promotion and achievement of decent work: social dialogue, social protection, employment creation, and international labor standards.

${ }^{8} \mathrm{We}$ also code references to corporate social responsibility (CSR) under international labor standards commitments when those are noted specifically in relation to LPs. Exception to this rule is our coding of references to CSR in the preamble which are by nature formulated in a more general manner.

${ }^{9}$ That is, PTA members have no right to veto a referral to third party adjudication.

${ }^{10}$ Domestic law commitments are not coded under C by design (i.e., implementation in the other parties' country is not an option). We also did not find such provisions.

${ }^{11}$ The classification of countries is based on the World Bank's 2017 Country and Lending Groups classification. We considered high-income countries to belong to the North and middle- and low-income countries to the South. High-income countries that are not OECD members include: Andorra, Antigua and Barbuda, The Bahamas, Bahrain, Barbados, Brunei Darussalam, Cyprus, Faroe Islands, Greenland, Hong Kong, Kuwait, Liechtenstein, Lithuania, Macao, Malta, Monaco, Oman, Palau, Qatar, San Marino, Saudi Arabia, Seychelles, Singapore, St. Kitts and Nevis, Taiwan, Trinidad and Tobago, United Arab Emirates, and Uruguay.

${ }^{12}$ For the EU and the European Free Trade Association (EFTA) we used the average number of PTAs with LPs across their member states.

${ }^{13}$ Should the Trans-Pacific Partnership (TPP 2016) be included, the US with 90 items coded under the TPP would have still preceded the EU in the last five-year window - although to a noticeably lesser extent.

${ }^{14}$ https://www.cigionline.org/articles/what-nafta-negotiators-can-do-about-worker-anxiety

15 Should the Comprehensive Economic and Trade Agreement (CETA 2016) be included, it would count among the exceptions.

${ }^{16}$ South-South PTAs with comprehensive LPs are: African Economic Community 1991; Common Market for Eastern and Southern Africa 1993; Economic Community Of West African States 1993; Eurasian Economic Community 1999; East African Community 1999; Caribbean Community 2001; China Peru 2009; East African Common Market 2009; Colombia Panama 2013.

${ }^{17}$ Given that Hofmann et al. (2017) use the year of the 'entry into force', we re-matched their PTAs with the DESTA's 'year of signing', the dates LABPTA is based on.

${ }^{18}$ ETUC Resolution for an EU progressive trade and investment policy (June 2017):

https://www.etuc.org/documents/etuc-resolution-eu-progressive-trade-and-investment-policy-adoptedexecutive-committee\#.WhsQ3kqnE2w; see also https://aflcio.org/statements/written-comments-how-makenafta-work-working-people

${ }^{19} \mathrm{http} / / /$ trade.ec.europa.eu/doclib/press/index.cfm?id=1803

${ }^{20} \mathrm{https} / /$ www.wto.org/english/thewto_e/minist_e/min01_e/mindecl_e.htm

${ }^{21}$ In the Canada-Chile (1996) PTA, quasi-judicial DSM is not available for the parties on the effective enforcement of domestic laws in general, but only should the effective enforcement concern "occupational safety and health, child labour or minimum wage technical labour standards" (Agreement on Labour Cooperation, Art. 25 (1)). 